\title{
Promiscuous G-Protein-Coupled Receptor Inhibition of Transient Receptor Potential Melastatin 3 Ion Channels by G $\beta \gamma$ Subunits
}

\author{
@Omar Alkhatib, ${ }^{1}$ @Robson da Costa, ${ }^{1,2}$ @Clive Gentry, ${ }^{1}$-Talisia Quallo, ${ }^{1}$ Stefanie Mannebach, ${ }^{3}$ Petra Weissgerber, ${ }^{3}$ \\ Marc Freichel, ${ }^{4,5}$ Stephan E. Philipp, ${ }^{3}{ }^{\circledR}$ Stuart Bevan, ${ }^{1}$ and $\odot$ David A. Andersson ${ }^{1}$ \\ ${ }^{1}$ Wolfson Centre for Age-Related Diseases, King's College London, London SE1 1UL, United Kingdom, ${ }^{2}$ School of Pharmacy, Universidade Federal do Rio \\ de Janeiro, 21941-908 Rio de Janeiro, Brazil, ${ }^{3}$ Experimental and Clinical Pharmacology and Toxicology/Center for Molecular Signaling (PZMS), Saarland \\ University, 66421 Homburg, Germany, ${ }^{4}$ Pharmacological Institute, Ruprecht-Karls-University Heidelberg, 69120 Heidelberg, Germany, and ${ }^{5} \mathrm{German}$ \\ Centre for Cardiovascular Research (DZHK), partner site Heidelberg/Mannheim, 69120 Heidelberg, Germany
}

Transient receptor potential melastatin 3 (TRPM3) is a nonselective cation channel that is inhibited by G $\beta \gamma$ subunits liberated following activation of $\mathrm{G} \alpha_{\mathrm{i} / \mathrm{o}}$ protein-coupled receptors. Here, we demonstrate that TRPM3 channels are also inhibited by $\mathrm{G} \beta \gamma$ released from $\mathrm{G} \alpha_{\mathrm{s}}$ and $\mathrm{G} \alpha_{\mathrm{q}}$. Activation of the $\mathrm{G}_{\mathrm{s}}$-coupled adenosine $2 \mathrm{~B}$ receptor and the $\mathrm{G}_{\mathrm{q}}$-coupled muscarinic acetylcholine $\mathrm{M} 1$ receptor inhibited the activity of TRPM3 heterologously expressed in HEK293 cells. This inhibition was prevented when the G $\beta \gamma$ sink $\beta$ ARK1-ct (C terminus of $\beta$-adrenergic receptor kinase-1) was coexpressed with TRPM3. In neurons isolated from mouse dorsal root ganglion (DRG), native TRPM3 channels were inhibited by activating $\mathrm{G}_{\mathrm{s}}$-coupled prostaglandin-EP2 and $\mathrm{G}_{\mathrm{q}}$-coupled bradykinin $\mathrm{B} 2$ (BK2) receptors. The $\mathrm{G}_{\mathrm{i} / \mathrm{o}}$ inhibitor pertussis toxin and inhibitors of PKA and PKC had no effect on EP2- and BK2-mediated inhibition of TRPM3, demonstrating that the receptors did not act through $\mathrm{G} \alpha_{\mathrm{i} / \mathrm{o}}$ or through the major protein kinases activated downstream of G-protein-coupled receptor (GPCR) activation. When DRG neurons were dialyzed with GRK2i, which sequesters free G $\beta \gamma$ protein, TRPM3 inhibition by EP2 and BK2 was significantly reduced. Intraplantar injections of EP2 or BK2 agonists inhibited both the nocifensive response evoked by TRPM3 agonists, and the heat hypersensitivity produced by Freund's Complete Adjuvant (FCA). Furthermore, FCA-induced heat hypersensitivity was completely reversed by the selective TRPM3 antagonist ononetin in WT mice and did not develop in $\operatorname{Trpm} 3^{-/-}$mice. Our results demonstrate that TRPM 3 is subject to promiscuous inhibition by $\mathrm{G} \beta \gamma$ protein in heterologous expression systems, primary neurons and in vivo, and suggest a critical role for this ion channel in inflammatory heat hypersensitivity.

Key words: DRG; G-protein beta-gamma; GPCR; ion channels; pain; TRPM3

Significance Statement

The ion channel TRPM3 is widely expressed in the nervous system. Recent studies showed that $\mathrm{G} \alpha_{\mathrm{i} / \mathrm{o}}$-coupled GPCRs inhibit TRPM3 through a direct interaction between $\mathrm{G} \beta \gamma$ subunits and TRPM3. Since $\mathrm{G} \beta \gamma$ proteins can be liberated from other $\mathrm{G} \alpha$ subunits than $\mathrm{G} \alpha_{\mathrm{i} / \mathrm{o}}$, we examined whether activation of $\mathrm{G}_{\mathrm{s}}$ - and $\mathrm{G}_{\mathrm{q}}$-coupled receptors also influence TRPM3 via $\mathrm{G} \beta \gamma$. Our results demonstrate that activation of $\mathrm{G}_{\mathrm{s}}$ - and $\mathrm{G}_{\mathrm{q}}$-coupled GPCRs in recombinant cells and sensory neurons inhibits TRPM3 via $\mathrm{G} \beta \gamma$ liberation. We also demonstrated that $\mathrm{G}_{\mathrm{s}}$ - and $\mathrm{G}_{\mathrm{q}}$-coupled receptors inhibit TRPM3 in vivo, thereby reducing pain produced by activation of TRPM3, and inflammatory heat hypersensitivity. Our results identify G $\beta \gamma$ inhibition of TRPM3 as an effector mechanism shared by the major $\mathrm{G} \alpha$ subunits.

\section{Introduction}

Transient receptor potential melastatin 3 (TRPM3) is a nonselective cation channel that is widely expressed in mammalian tis- sues. TRPM3 is present in peripheral sensory neurons where it may act as a heat sensor and its activation in vivo evokes nociceptive behaviors in mice (Vriens et al., 2011). TRPM3 can be activated by the endogenous neurosteroid pregnenolone sulfate (PS), which has been used as a pharmacological tool to study the

This work was supported in part by Medical Research Council UK Grant MR/L010747/1, Saudi Arabian Custodian of the Two Holy Mosques Scholarship to 0.A., Coordenação de Aperfeiçoamento de Pessoal de Nível Superior Brazil (CAPES, finance code 001), the Royal Society UK Newton International Fellowship to R.d.C., the DZHK 
channel (Wagner et al., 2008). In studies of isolated dorsal root ganglion (DRG) neurons, PS application evoked increases in intracellular $\mathrm{Ca}^{2+}$ concentrations $\left(\left[\mathrm{Ca}^{2+}\right]_{\mathrm{i}}\right)$ in $\sim 58 \%$ of cells $(\mathrm{Vr}-$ iens et al., 2011), and a high proportion of TRPM3-expressing DRG neurons also expressed TRPV1 (Vriens et al., 2011), identifying these neurons as nociceptors. Trpm $3^{-1-}$ mice exhibit compromised behavioral responses to noxious heat, altered temperature preferences, and fail to develop heat hyperalgesia associated with inflammation (Vriens et al., 2011).

Like most TRP channels, the activity of TRPM3 can be inhibited by phospholipase C-mediated PtdIns $(4,5) \mathrm{P}_{2}$ hydrolysis (Rohacs, 2014). We recently demonstrated, along with two other groups, that activation of $\mathrm{G}_{\mathrm{i} / \mathrm{o}}$-coupled GPCRs inhibits TRPM3 both in vitro and in vivo (Badheka et al., 2017; Dembla et al., 2017; Quallo et al., 2017). TRPM3 can also be inhibited by activation of heterologously expressed $\mathrm{G}_{\mathrm{q}}$-coupled GPCRs in recombinant systems (Badheka et al., 2017). This inhibition is independent of $\mathrm{G} \alpha_{\mathrm{i} / \mathrm{o}}$ and $\mathrm{G} \alpha_{\mathrm{q}}$ subunits and is due to the direct interaction of G $\beta \gamma$ subunits with TRPM3 because direct application of G $\beta \gamma$ to the intracellular face of excised inside-out patches inhibits the channel and TRPM3 can be coimmunoprecipitated together with G $\beta \gamma$ (Badheka et al., 2017; Dembla et al., 2017; Quallo et al., 2017). Earlier studies of some voltage-gated calcium channels (VGCCs) and G protein-coupled inwardly-rectifying potassium channels (GIRKs) have shown that these can be promiscuously modulated by $\mathrm{G} \beta \gamma$ released from different $\mathrm{G} \alpha$ subunits (for review, see Dascal, 1997; Yamada et al., 1998; Dolphin, 2003). We therefore examined whether activation of $\mathrm{G}_{\mathrm{s}}$-coupled GPCRs can similarly modulate TRPM3 through liberated G $\beta \gamma$ subunits. Additionally, we assessed whether $\mathrm{G}_{\mathrm{q}}$-coupled GPCR activation modulates TRPM3 activity in native sensory neurons and in vivo.

We have used endogenously and heterologously expressed $\mathrm{G}_{\mathrm{s}}-$ coupled adenosine 2B (A2B) receptors in HEK293 cells heterologously expressing TRPM3. We also studied the influence of natively expressed $\mathrm{G}_{\mathrm{s}}$-coupled prostaglandin EP2 and $\mathrm{G}_{\mathrm{q}}$-coupled bradykinin $\mathrm{B} 2$ receptors on TRPM3 in mouse isolated DRG neurons. Our results demonstrate that activation of $\mathrm{G}_{\mathrm{s}}$ - and $\mathrm{G}_{\mathrm{q}}$-coupled GPCRs inhibits TRPM3 through a direct interaction with $\mathrm{G} \beta \gamma$ subunits. The inhibition of TRPM3 by $\mathrm{G}_{\mathrm{s}}$ - and $\mathrm{G}_{\mathrm{q}}$-coupled GPCRs also operated in DRG neurons and in vivo, where GPCR agonists reduced pain-related behaviors evoked by activation of TRPM3, as well as the heat hyperalgesia associated with inflammation.

\section{Materials and Methods}

Mice. Male and female wild type (WT) C57BL/6J, WT C57BL/6N, and TRPM3-KO (Trpm3 $3^{-/-}$; C57BL/6N background) mice were used. The TRPM3-deficient mouse line was generated as described in detail in Extended Data 1. Mice were kept in a climatically controlled environment with ad libitum access to food and water and were acclimatized in the procedure room for $1 \mathrm{~h}$ before the experiments. All behavioral experiments were approved by the King's College London Animal Welfare and Ethical Review Board and conducted under the UK Home Office Project License (PF0C9D185).

Cell culture. DRG neurons were prepared from adult male and female C57BL/6J mice using methods described previously (Bevan and Winter, 1995). Isolated neurons were plated on poly-D-lysine-coated coverslips

(German Centre for Cardiovascular Research), the BMBF (German Ministry of Education and Research), the DFG (German Research Foundation) Project-ID 239283807-TRR 152 and the FOR 2289 to M.F. and by the DFG (SFB 894) and Saarland University [HOMFOR] to S.E.P.

The authors declare no competing financial interests.

Correspondence should be addressed to David A. Andersson at david.andersson@kcl.ac.uk or Omar Alkhatib at omar.alkhatib@kcl.ac.uk.

https://doi.org/10.1523/JNEUROSCI.0882-19.2019

Copyright $@ 2019$ the authors and maintained at $37^{\circ} \mathrm{C}$ in an atmosphere of $95 \%$ air and $5 \% \mathrm{CO}_{2}$ in MEM AQ (Sigma-Aldrich) supplemented with $10 \%$ FBS, $100 \mathrm{U} / \mathrm{ml}$ penicillin, $100 \mu \mathrm{g} / \mathrm{ml}$ streptomycin, and $50 \mathrm{ng} / \mathrm{ml} \mathrm{NGF}$ (Promega) for up to $24 \mathrm{~h}$ before experimentation. Untransfected HEK293 cells (RRID: CVCL_U427, Thermo Fisher Scientific) were grown in DMEM AQ supplemented with penicillin $(100 \mathrm{U} / \mathrm{ml})$, streptomycin $(100 \mu \mathrm{g} / \mathrm{ml})$, and FBS (10\%). HEK293 cells stably expressing TRPM3 $\alpha 2$ plasmid (pcDNA3.1) DNA were grown in DMEM AQ supplemented with penicillin $(100 \mathrm{U} / \mathrm{ml})$, streptomycin $(100 \mu \mathrm{g} / \mathrm{ml})$, FBS (10\%), and G418 (0.5 $\mathrm{mg} / \mathrm{ml}$ ). HEK293 cells stably expressing pGloSensonsor-22F (Promega) were grown in DMEM AQ supplemented with penicillin $(100 \mathrm{U} / \mathrm{ml})$, streptomycin $(100 \mu \mathrm{g} / \mathrm{ml})$, FBS $(10 \%)$, and hygromycin $(200 \mu \mathrm{g} / \mathrm{ml})$. For some experiments, TRPM3 HEK293 cells were transiently transfected with plasmids encoding pEYFP-N1-A2BR (a gift from Robert Tarran, Addgene plasmid \#37202), pRK5 BARK1 minigene (a gift from Robert Lefkowitz, Addgene plasmid \#14695; http://n2t.net/addgene: 14695; RRID:Addgene_14695) and muscarinic M1 receptor (a gift from David Julius), using Lipofectamine 2000 according to the supplier's protocol. All cells used were mycoplasma free.

Imaging intracellular calcium concentrations. DRG neurons and TRPM3 HEK293 cells were loaded with $2.5 \mu \mathrm{M}$ fura-2 AM (Invitrogen) in the presence of $1 \mathrm{~mm}$ probenecid (Tocris Bioscience) for 1-1.5 h. Dye loading and all experiments were performed in a physiological saline solution containing the following (in $\mathrm{mm}$ ): $140 \mathrm{NaCl}, 5 \mathrm{KCl}, 10$ glucose, 10 HEPES, $2 \mathrm{CaCl}_{2}$, and $1 \mathrm{MgCl}_{2}$, buffered to $\mathrm{pH} 7.4(\mathrm{NaOH})$. Drug solutions were applied to cells by local microsuperfusion of solution through a fine tube placed very close to the cells being studied. The temperature of the superfused solution $\left(25^{\circ} \mathrm{C}\right)$ was regulated by a temperature controller (Marlow Industries) attached to a Peltier device with the temperature measured at the outlet orifice of the microperfusion tube. Images of a group of cells were captured every $2 \mathrm{~s}$ at 340 and $380 \mathrm{~nm}$ excitation wavelengths with emission measured at $520 \mathrm{~nm}$ with a microscope-based imaging system (PTI). Analyses of emission intensity ratios at $340 \mathrm{~nm} / 380 \mathrm{~nm}$ excitation were performed with the ImageMaster suite of software.

Multiwell readings of calcium and cAMP levels. To monitor intracellular cAMP levels, we used the pGLOSensor-22F plasmid, which is a biosensor for cAMP that is able to respond rapidly and reversibly to changes in the intracellular concentration of cAMP (Binkowski et al., 2009). Untransfected and pGLOSensor-22F HEK293 cells were plated in poly-D-lysinecoated 96-well black-walled plates (Corning Costar) 1-2 d before experimentation. Cells were loaded with fura- 2 using the protocol described above. When measuring changes in intracellular cAMP levels, pGLOSensor-22F-expressing HEK293 cells were loaded with GloSensor (Promega) diluted in physiological saline solution for $45 \mathrm{~min}$ before experimentation. In both assays, wells were injected with compounds and responses read using the FlexStation 3 Multi-Mode Microplate Reader (Molecular Devices) using appropriate excitation and emission wavelengths (340/380 excitation, 520 emission for fura- 2 and luminescence for Glosensor).

Electrophysiology. DRG neurons and TRPM3-expressing HEK293 cells were studied under voltage-clamp conditions using an Axopatch 200B amplifier and pClamp 10.0 software (RRID:SCR_011323, Molecular Devices). Recordings were performed at $+60 \mathrm{mV}$ using borosilicate electrodes $(2.5-5 \mathrm{M} \Omega$ ) filled with a solution containing the following (in mM): $140 \mathrm{CsCl}, 10$ EGTA, 2 MgATP, and $2 \mathrm{Na}_{2} \mathrm{ATP}$, buffered to $\mathrm{pH} 7.4$ (CsOH). In some experiments, $500 \mu \mathrm{M}$ GDP $\beta S$ or $300 \mu \mathrm{M}$ GTP $\gamma S$ was also included in the intracellular solution. The extracellular solution was the same used for the $\left[\mathrm{Ca}^{2+}\right]_{\mathrm{i}}$ measurements (see above).

Behavioral assessment of pain responses. Male C57BL/6J mice (6-10 per group) were administered by intraplantar injection with a combination of PS ( $5 \mathrm{nmol}$ ) and CIM0216 ( $0.5 \mathrm{nmol}$ in $25 \mu \mathrm{l}$ in PBS) or capsaicin (5 $\mathrm{nmol}$ in $25 \mu \mathrm{l}$ in PBS) into one of the hindpaws using Luer syringe (Hamilton) fitted with a 26 -guage $\times 3 / 8$ inch needle. Bradykinin was injected $5 \mathrm{~min}$ and $\mathrm{PGE}_{2}$ and butaprost $(0.3 \mathrm{nmol}$ each in $20 \mu \mathrm{l}$, intraplantar, each) were injected $10 \mathrm{~min}$ before PS/CIM0216 or capsaicin. Mice were habituated to the experimental Perspex chambers before the experiment and placed in the chambers immediately after injection of the compounds. The duration of pain-related behaviors (licking, biting, 
A

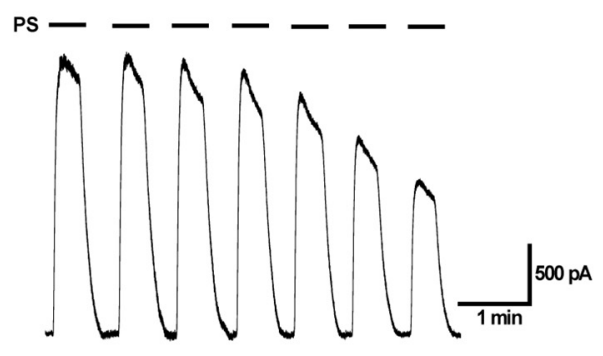

D

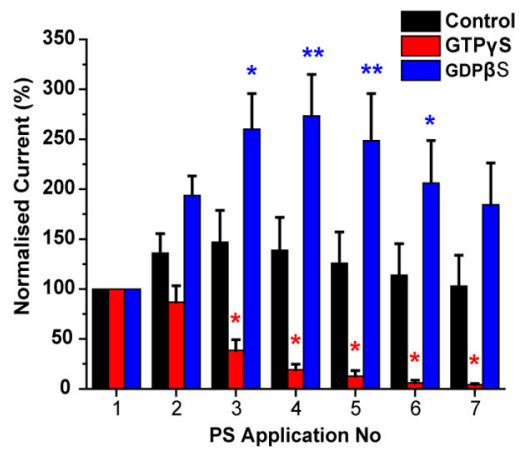

B

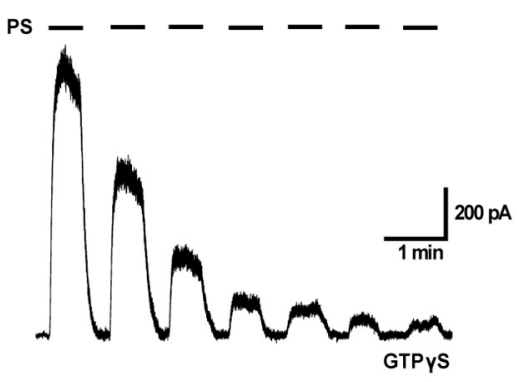

C

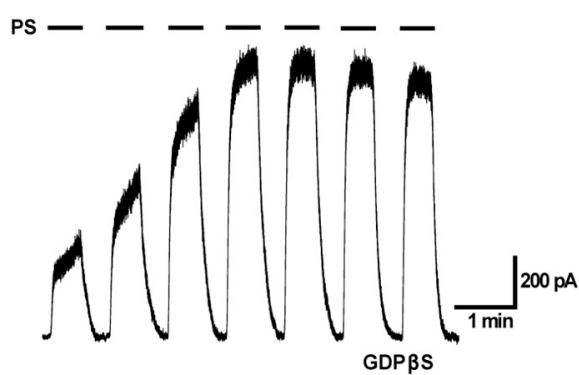

$\mathbf{F}$
E

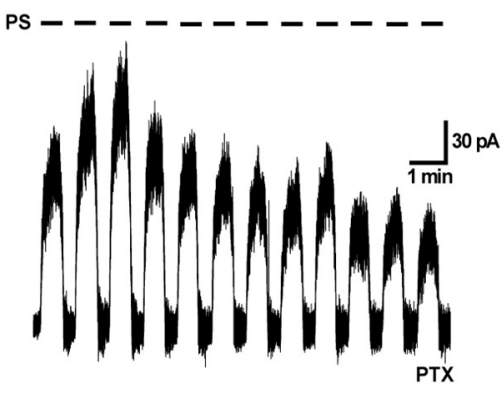

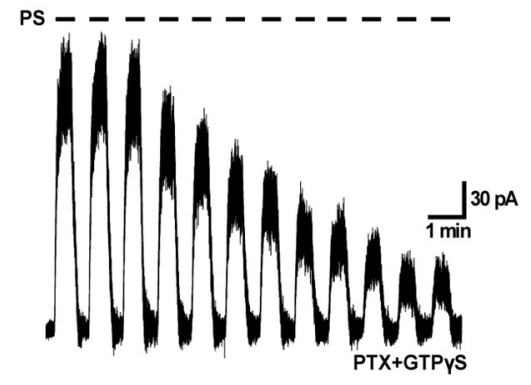

G

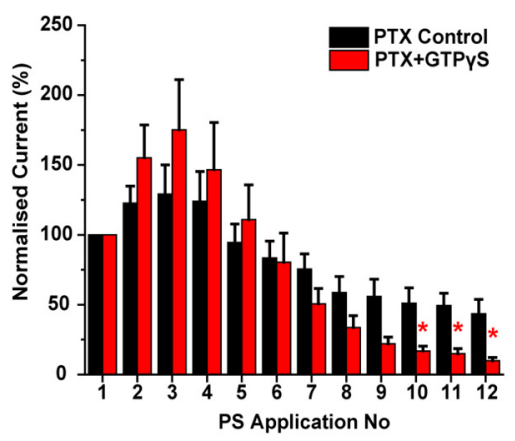

Figure 1. Non- $\mathrm{G}_{\mathrm{i} / 0}$-mediated inhibition of TRPM3. A-C, Example traces of multiple applications of PS (100 $\mu \mathrm{m}$ ) in whole-cell voltage-clamp recordings ( $\left.+60 \mathrm{mV}\right)$ of TRPM3 HEK293 cells with control, GTP $\gamma S(300 \mu \mathrm{M})$, or GDP $\beta S(500 \mu \mathrm{M})$ intracellular solutions. $\boldsymbol{D}$, Bar chart of the average responses \pm SEM of $(\boldsymbol{A})(n=7),(\boldsymbol{B})(n=6)$, and $(\boldsymbol{C})(n=8)\left(F_{(2,18)}=11.8, p=0.0005\right) . \boldsymbol{E}, \boldsymbol{F}$, Example traces of multiple applications of PS $(100 \mu \mathrm{m})$ in whole-cell voltage-clamp recordings (60 mV) of TRPM3 HEK293 cells treated with PTX (200 ng/ml) with control or GTP $\gamma S$ (300 $\mu \mathrm{m})$ intracellular solutions. $\boldsymbol{G}$, Bar chart of the average responses \pm SEM of $(\boldsymbol{E})(n=7$ or 8$)$ and $(\boldsymbol{F})(n=9$ or 10$)\left(t_{(14)}=3.62, p=0.028\right) .{ }^{*} p<0.05$; ** $p<0.01$; compared with control, repeated-measures two-way ANOVA with Dunnett's multiple-comparisons test (D) and multiple $t$ test (G).

flinching, shaking, and elevating the injected paw) were recorded using a digital stopwatch. Total pain response times over the first 2 min were used for analysis as the pain behaviors were largely restricted to this period.

Male and female WT C57BL/6J, C57BL/6N, and Trpm $3^{-/-}$C57BL/6N mice (6-8 per group) were injected with Freund's Complete Adjuvant (FCA; $15 \mu \mathrm{l}$ ) in one of the hindpaws. Paw withdrawal latencies from the hotplate were assessed before and $72 \mathrm{~h}$ after FCA injection. Thermal nociception was examined by lightly restraining the animal and placing one of the hindpaws onto a hotplate maintained at $50^{\circ} \mathrm{C}$ (Andersson et al., 2011). The paw withdrawal latency was measured using $30 \mathrm{~s}$ as a cutoff to avoid tissue damage. To assess the effects of ononetin, $\mathrm{PGE}_{2}$, or bradykinin, paw withdrawal latencies in FCA-injected mice were also measured $1 \mathrm{~h}$ after administration of ononetin (10 mg/kg, i.p.), and 10 min and 5 min after intraplantar administration of $\mathrm{PGE}_{2}$ and bradykinin.

Materials. Stock solutions of PS, capsaicin, forskolin (Sigma-Aldrich), bisindolylmaleimide VIII, butaprost (Cayman Chemical), BAY 606583, CIM0216, PSB 603, KT 5720 (Tocris Bioscience), and SSR240612 (Sanofi Aventis) were prepared in DMSO. Stock solutions of GRK2i, carbachol, 2-furoyl-LIGRLO-amide, adenosine, bradykinin, HOE 140 (Tocris Bioscience), and morphine sulfate (Sigma-Aldrich) were made in $\mathrm{H}_{2} \mathrm{O}$, and $\mathrm{PGE}_{2}$ (Sigma-Aldrich) and CAY10598 (Cayman Chemical) in ethanol. Pertussis toxin (PTX, $0.2 \mathrm{mg} / \mathrm{ml}$; SigmaAldrich) was diluted in cell culture AQMEM media. GTP $\gamma S$ and GDP $\beta$ S (Sigma-Aldrich) were added to the intracellular solution. FCA was obtained from Sigma-Aldrich.

Experimental design and statistical analyses. Data are presented as box plots showing the mean (square symbol), median (horizontal line), and SEM (box). For imaging and electrophysiology experiments, $n$ indicates the number of PS responding neurons or cells; for multiwell experiments, $n$ indicates the number of independent experiments performed (each in triplicate wells); and in behavioral experiments, $n$ values indicate the number of animals in each group. A priori power calculations were not performed, but our sample sizes are similar to, or greater than, those generally used in the field. Normality of data was tested using the Shapiro-Wilk Test. Normally distributed data were analyzed using an independent-samples $t$ test. Differences in normally distributed data means between three groups or more were analyzed using two-way and repeated-measures ANOVA, followed by Tukey's or Dunnett's multiple-comparisons post hoc test. Differences in non-normally distributed data means between two groups were analyzed using a Mann-Whit- 
A

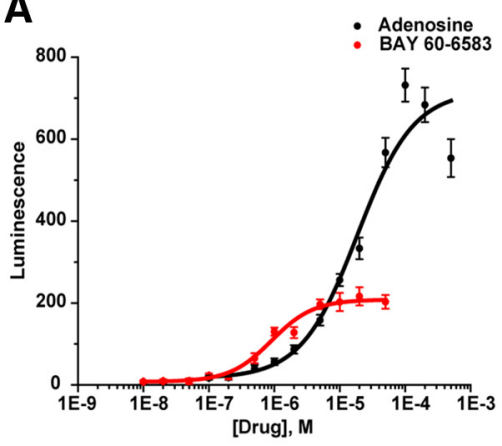

D

PS

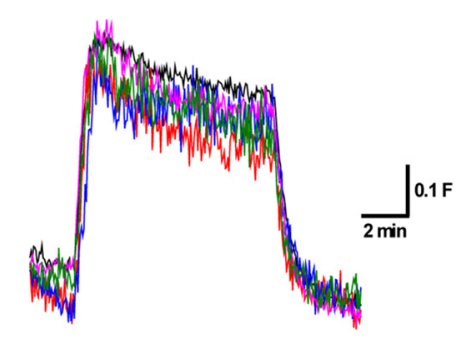

G

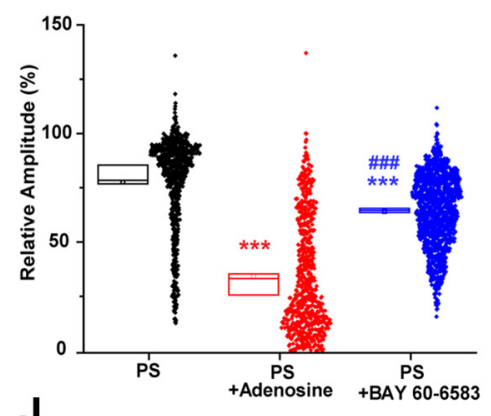

J

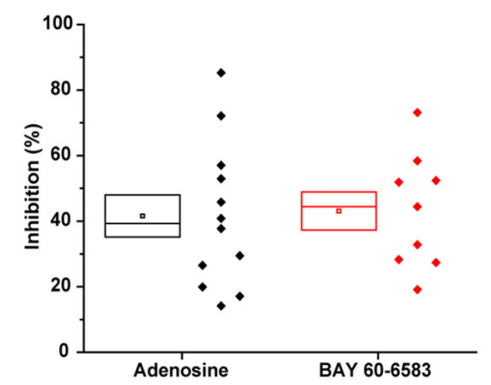

M

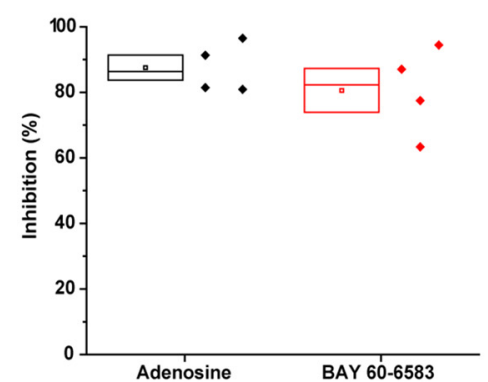

B

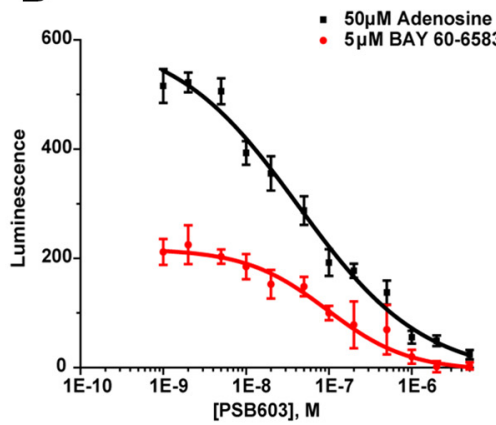

E

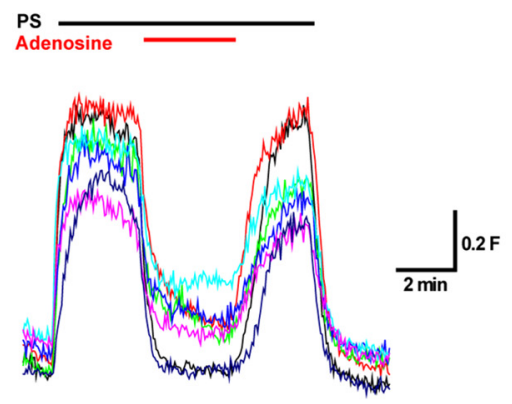

H
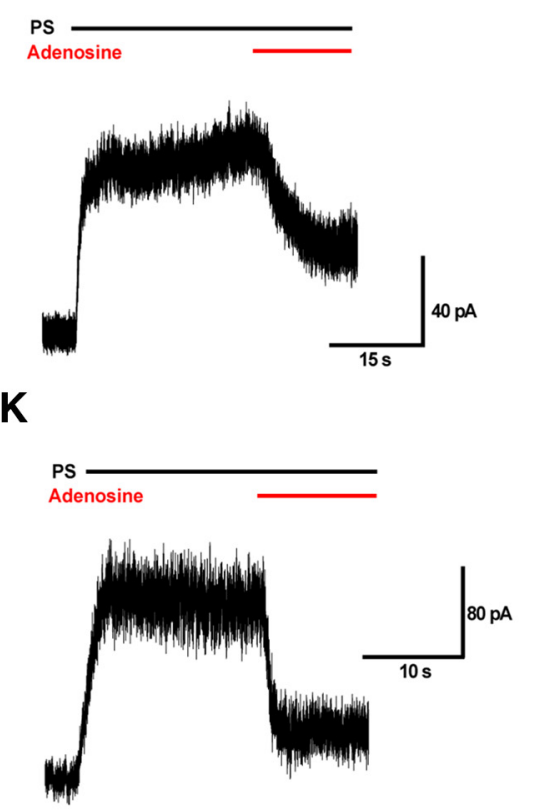

C

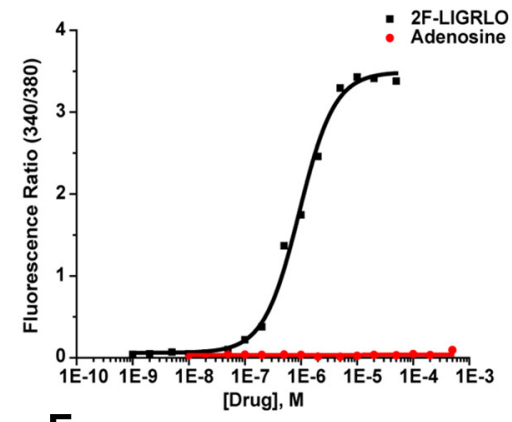

F

BAY $\overline{60-6583-}$

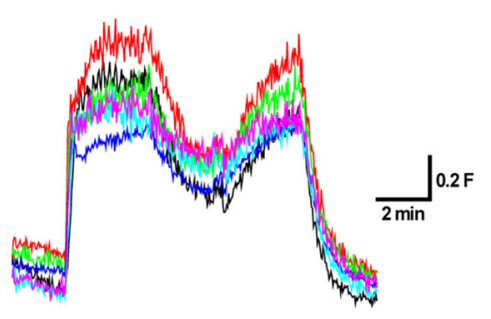

I

PS

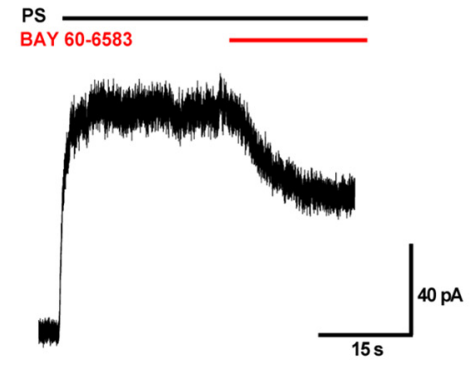

L

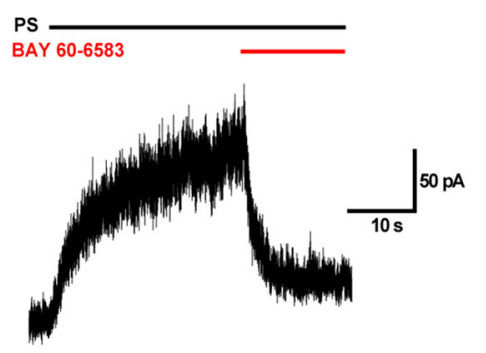

Figure 2. $\mathrm{G}_{\mathrm{s}}$-coupled adenosine 2B receptor activation inhibits TRPM3-mediated responses in HEK293 cells. $A$, Concentration response curves of intracellular cAMP production in response to adenosine or BAY $60-6583$ application mean \pm SEM in pGLOSensor HEK293 cells. B, Inhibitory concentration response curves using the selective A2B antagonist, PSB603, on intracellular cAMP production evoked by adenosine $(50 \mu \mathrm{m})$ or BAY $60-6583(5 \mu \mathrm{m})$ mean \pm SEM. C, Concentration response curve of $\left[\mathrm{Ca}^{2+}\right]_{\mathrm{i}}$ responses in HEK293 cells following application of $2 \mathrm{~F}-\mathrm{LIGRL} 0$ or adenosine mean \pm SEM $\left(n=4\right.$, both). $\boldsymbol{D},\left[\mathrm{Ca}^{2+}\right]_{\mathrm{i}}$ responses in TRPM3 HEK293 cells with PS application $(20 \mu \mathrm{M}) . \boldsymbol{E}, \boldsymbol{F},\left[\mathrm{Ca}^{2+}\right]_{\mathrm{i}}$ responses in TRPM3 (Figure legend continues.) 
ney $U$ test. Differences in non-normally distributed data means between three groups or more were analyzed using a Kruskal-Wallis test, followed by a Dunn's multiple-comparisons post hoc test. All statistical analyses were made using Prism version 7 (GraphPad).

Relative amplitudes in $\left[\mathrm{Ca}^{2+}\right]_{\mathrm{i}}$ imaging experiments were calculated by comparing the minimum response amplitude during the coapplication of PS and GPCR agonists (3-6 min time point) to the maximum amplitude during PS application (0-3 min time point). All PS-responsive cells were included in the analysis.

The effect of GPCR agonist application on PS-evoked currents in patch-clamp electrophysiology were calculated in a similar manner and represented as the percentage inhibition of the maximal PS response.

\section{Results}

\section{Non- $G_{i / o}$-mediated inhibition of TRPM3}

Because $\mathrm{G}_{\mathrm{i} / \mathrm{o}}$-coupled GPCRs inhibit TRPM3 by an interaction with G $\beta \gamma$ (Badheka et al., 2017; Dembla et al., 2017; Quallo et al., 2017), we examined whether $\mathrm{G} \beta \gamma$ subunits liberated by other $\mathrm{G} \alpha$ proteins can exert a similar influence on TRPM3. To assess the effects of the irreversible $\mathrm{G} \alpha$ activator GTP $\gamma \mathrm{S}$ and inhibitor GDP $\beta S$, we studied HEK293 cells stably expressing TRPM3 by voltage clamp. In the absence of either GTP analog, currents evoked by repeated application of PS $(100 \mu \mathrm{M})$ showed a timedependent, but modest, decline in amplitude (Fig. $1 A, D$ ). Inclusion of GTP $\gamma S(300 \mu \mathrm{M})$ in the pipette solution significantly accelerated the desensitization of TRPM3 after $\sim 3$ min (third PS application) (Fig. $1 B, D$ ). In contrast, dialyzing the cell with GDP $\beta S(500 \mu \mathrm{M})$ led to a progressive and significant increase in the PS-evoked current amplitude, which reached a maximum after $\sim 4 \mathrm{~min}$ (fourth PS application) (Fig. 1C,D). To test whether the effects of GTP $\gamma \mathrm{S}$ were partly mediated by non- $\mathrm{G}_{\mathrm{i} / \mathrm{o}}$ signaling, we incubated the cells with PTX (200 ng/ml, for $24 \mathrm{~h}$ ), which specifically locks the $\alpha_{\mathrm{i} / \mathrm{o}}$ subunits into an inactive, GDP-bound state and inhibits $\mathrm{G} \alpha_{\mathrm{i} / \mathrm{o}}$ subunits coupling to their cognate GPCRs. GTP $\gamma S$ was still able to inhibit PS-evoked currents in PTXtreated cells, albeit more slowly than in the absence of PTX (10th PS application) (Fig. $1 E-G$ ), which is consistent with a mechanism independent of $\mathrm{G}_{\mathrm{i} / \mathrm{o}}$ signaling.

\section{$\mathrm{G}_{\mathrm{s}}$-mediated inhibition of TRPM3}

Because our experiments with GTP $\gamma \mathrm{S}$ demonstrate that G-proteins other than $G_{i / o}$ can inhibit TRPM3 currents, we examined the effects of agonists of GPCRs coupled to G $\alpha_{\mathrm{s}}$ on TRPM3 activity. The adenosine A2B receptor is expressed at high levels in HEK293 cells (Cooper et al., 1997) and couples to $\mathrm{G} \alpha$, thereby generating substantially increased intracellular cAMP upon stimulation. To confirm that the receptor is expressed in our cell line, we used HEK293 cells stably expressing the pGLOSensor (Binkowski et

\footnotetext{
(Figure legend continued.) HEK293 cells treated with PS $(20 \mu \mathrm{m})$ and adenosine $(100 \mu \mathrm{M})$ or BAY $60-6583(20 \mu \mathrm{M})$. G, Scatter plot representing the mean, median, and SEM of the relative amplitude from $(\boldsymbol{D})(n=731),(\boldsymbol{E})(n=588)$, and $(\boldsymbol{F})(n=1145)$. The minimum response amplitude during coapplication of $\mathrm{PS}$ and $\mathrm{A} 2 \mathrm{~B}$ agonists was compared with the maximum amplitude during PS application. $\boldsymbol{H}, \boldsymbol{I}$, Example traces of adenosine $(100 \mu \mathrm{M})$ and BAY $60-6583$ $(20 \mu \mathrm{M})$ mediated inhibition of PS $(100 \mu \mathrm{m})$ evoked currents in whole-cell voltage-clamp recordings $(+60 \mathrm{mV}$ ) in TRPM3 HEK293 cells. J, Scatter plot representing TRPM3-evoked current inhibition in $(\boldsymbol{H})(n=12)$ and $(\boldsymbol{I})(n=9)\left(t_{(19)}=0.17, p=0.867\right.$, two-tailed unpaired $t$-test). $\boldsymbol{K}, \boldsymbol{L}$, Example traces of adenosine $(100 \mu \mathrm{M})$ and BAY $60-6583(20 \mu \mathrm{M})$ mediated inhibition of PS (100 $\mu \mathrm{M})$ evoked currents in whole-cell voltage-clamp recordings $(60 \mathrm{mV})$ in TRPM3 and A2B transfected HEK293 cells. M, Scatter plot representing TRPM3-evoked current inhibition in $\boldsymbol{K}$ and $\boldsymbol{L}\left(n=4\right.$, both) $\left(t_{(6)}=0.902, p=0.402\right.$, two-tailed unpaired $t$-test). ${ }^{* * *} p<0.001$ compared with control; ${ }^{* \#} p<0.001$ compared with adenosine treatment; Kruskal-Wallis with Dunn's multiple-comparisons test.
}

al., 2009) to monitor the effect of A2B agonists on cAMP levels. Application of the endogenous full agonist adenosine or the selective partial A2B agonist BAY 60-6583 (Hinz et al., 2014) produced robust intracellular cAMP responses (Fig. 2A). The response profile and $\mathrm{pEC}_{50}$ values of adenosine $(4.75 \pm 0.05$ SEM, $n=4)$ and BAY 60-6583 (6.04 \pm 0.18 SEM, $n=4)$ agree with previous studies (Goulding et al., 2018). To confirm that both agonists produced cAMP by activating the $\mathrm{A} 2 \mathrm{~B}$ receptor, we generated inhibitory concentration response curves using the selective A2B antagonist PSB603 and submaximally effective $\left(\mathrm{EC}_{80}\right)$ concentrations of adenosine $(50 \mu \mathrm{M})$ and BAY $60-6583$ $(5 \mu \mathrm{M})$. PSB603 inhibited the responses with a similar $\mathrm{pIC}_{50}$ for both adenosine $(7.18 \pm 0.15 \mathrm{SEM}, n=4)$ and BAY $60-6583$ $(6.71 \pm 0.3 \mathrm{SEM}, n=4)$ and almost completely inhibited intracellular CAMP responses at the highest concentrations tested (Fig. $2 B)$. To assess whether A2B can also couple to $\mathrm{G} \alpha$, we applied adenosine and used fura-2 to measure $\left[\mathrm{Ca}^{2+}\right]_{\mathrm{i}}$ (Fig. $2 \mathrm{C}$ ). As a positive control for $\mathrm{G}_{\mathrm{q}}$-mediated $\left[\mathrm{Ca}^{2+}\right]_{\mathrm{i}}$ increases, we used the selective PAR2 agonist, 2-furyl LIGRLO- $\mathrm{NH}_{2}$ (2F-LIGRLO), as the receptor has been shown to couple to $\mathrm{G} \alpha_{\mathrm{q}}$ and produce calcium responses in HEK293 cells (Kawabata et al., 1999). Stimulation of $\mathrm{A} 2 \mathrm{~B}$ evoked substantial intracellular cAMP production, but no detectable increase in $\left[\mathrm{Ca}^{2+}\right]_{\mathrm{i}}$ (Fig. $2 \mathrm{~A}, \mathrm{C}$ ), and we therefore used activation of the $\mathrm{A} 2 \mathrm{~B}$ receptor to explore the influence of $\mathrm{G}_{\mathrm{s}}$-mediated activity on TRPM3.

The TRPM3 agonist PS $(20 \mu \mathrm{M})$ evoked $\left[\mathrm{Ca}^{2+}\right]_{\mathrm{i}}$ increases in TRPM3-expressing HEK293 cells, which were only subject to a minor degree of desensitization during the 9 min application period $(22.4 \pm 0.81 \%$ of reduction; Fig. $2 D, G)$. A2B receptor stimulation with adenosine $(100 \mu \mathrm{M})$ or BAY $60-6583(20 \mu \mathrm{M})$ significantly and reversibly reduced the amplitudes of the TRPM3-mediated responses by $65.8 \% \pm 1.1 \%$ and $35.9 \% \pm$ $0.5 \%$ (Fig. $2 E-G$ ). The smaller degree of inhibition produced by BAY 60-6583 is consistent with its properties as a partial agonist at A2B receptors (Hinz et al., 2014) (Fig. 2A,G). Next, we used patch-clamp recordings to confirm that the observed $\mathrm{A} 2 \mathrm{~B}$ mediated inhibition of PS-evoked $\left[\mathrm{Ca}^{2+}\right]_{\mathrm{i}}$ responses was associated with a corresponding inhibition of TRPM3 currents. Adenosine $(100 \mu \mathrm{M})$ and BAY 60-6583 $(20 \mu \mathrm{M})$ significantly inhibited PS-evoked $(100 \mu \mathrm{M})$ currents to a similar extent (by $41.6 \pm 6.4 \%$ and $43.1 \pm 5.8 \%$ ) (Fig. $2 H-J$ ). Since the current inhibition achieved by A2B stimulation was variable, we repeated the experiments using TRPM3 HEK293 cells overexpressing the $\mathrm{A} 2 \mathrm{~B}$ receptor. Overexpression of $\mathrm{A} 2 \mathrm{~B}$ generated more uniform and robust inhibition of PS-evoked currents (by $87.5 \pm 3.8 \%$ for adenosine and $80.6 \pm 6.7 \%$ for BAY $60-6583$ ) (Fig. $2 K-M$ ). Together, these observations demonstrate that $\mathrm{G}_{\mathrm{s}}$-coupled GPCR activation can inhibit TRPM3.

\section{$\mathrm{G}_{\mathrm{s}}$-mediated inhibition of TRPM3 in sensory neurons}

We next measured $\left[\mathrm{Ca}^{2+}\right]_{\mathrm{i}}$ responses in isolated mouse DRG neurons to confirm that the $\mathrm{G}_{\mathrm{s}}$-mediated inhibition of TRPM3 operates in native cells. PS $(20 \mu \mathrm{M})$ was applied to evoke a response and agonists of different GPCRs were coadministered as described for HEK293 cell experiments above. Continuous application of PS evoked a sustained increase in $\left[\mathrm{Ca}^{2+}\right]_{i}$ in DRG neurons (Fig. 3A). In control experiments, the amplitude of PSevoked responses after 9 min of application was reduced by $17.8 \pm 1.2 \%$ of the maximal response amplitude, consistent with a small degree of desensitization (Fig. 3C). Applications of the inflammatory mediator $\mathrm{PGE}_{2}(1 \mu \mathrm{M})$, which has been widely used to sensitize nociceptive afferents (Meves, 2006), strongly inhibited PS-induced $\left[\mathrm{Ca}^{2+}\right]_{\mathrm{i}}$ responses in a subpopulation of 
A

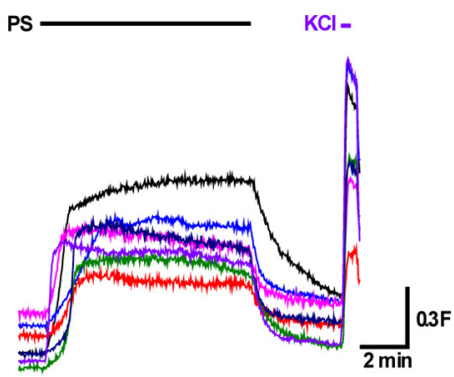

D

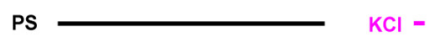

Morphine

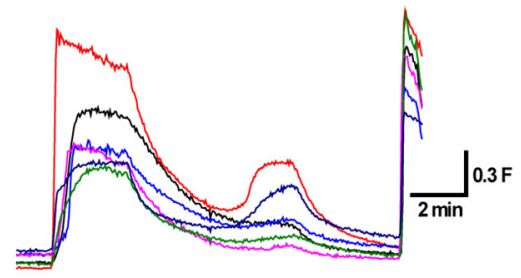

G

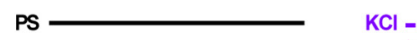

Butaprost

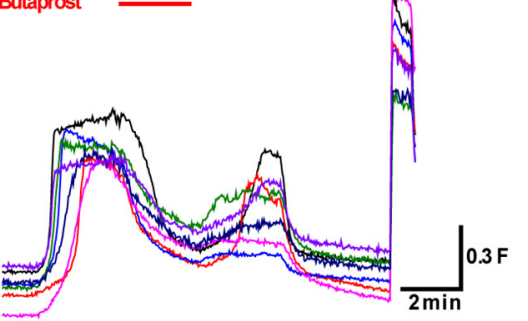

J

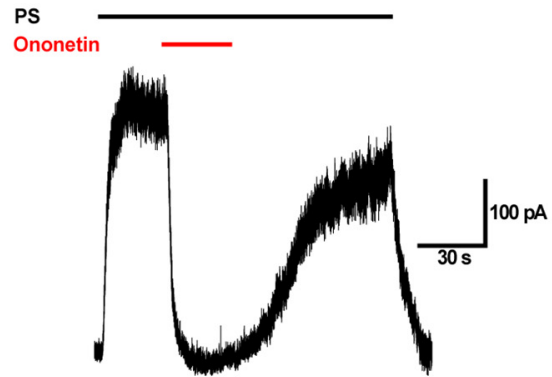

B

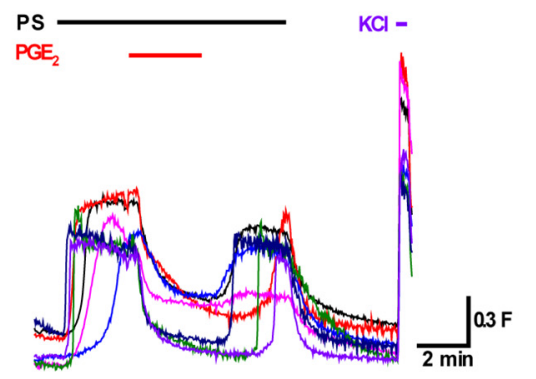

E

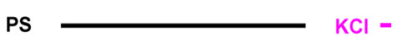

Morphine

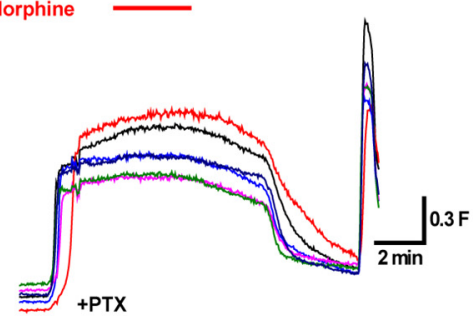

H

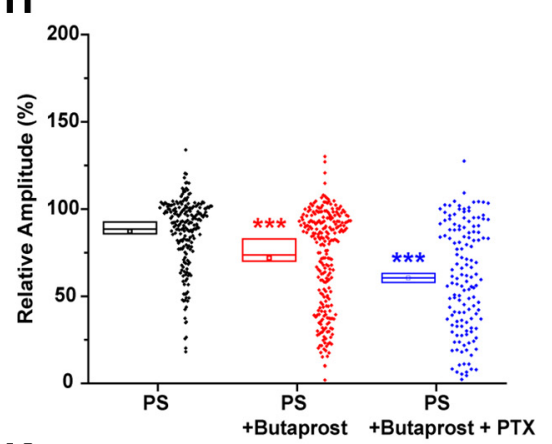

K

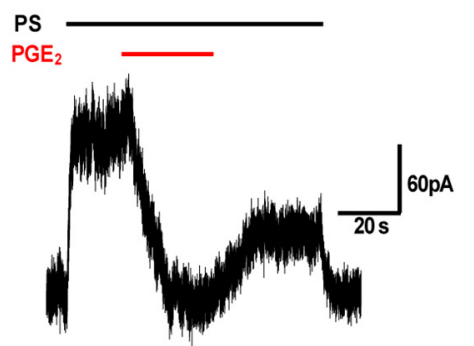

C

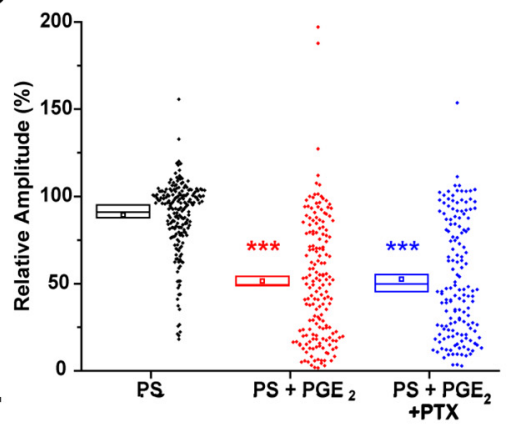

F

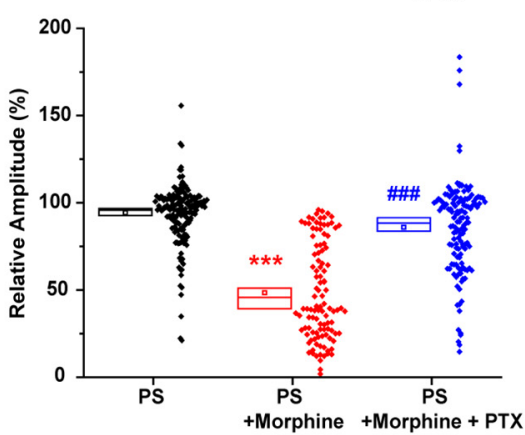

I

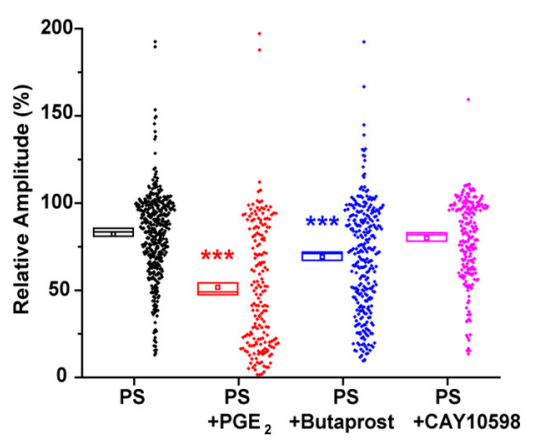

L

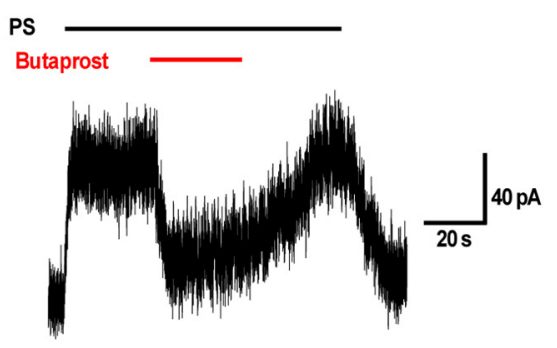

M

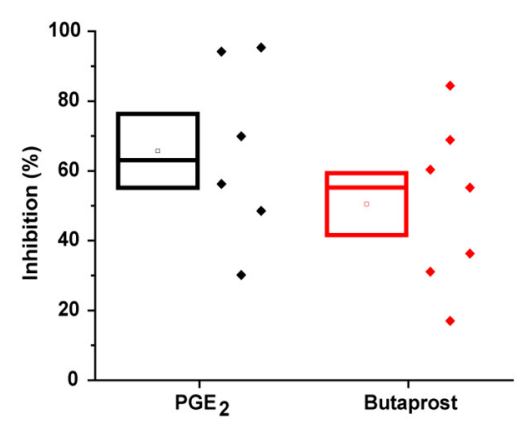

Figure 3. Prostaglandin EP2 receptor activation inhibits TRPM3-mediated responses in sensory neurons. $A_{1}\left[\mathrm{Ca}^{2+}\right]_{\mathrm{i}}$ responses in isolated mouse DRG neurons challenged by PS (20 $\left.\mu \mathrm{M}\right)$ followed by $\mathrm{KCl}(50 \mathrm{~mm})$ application. $\boldsymbol{B},\left[\mathrm{Ca}^{2+}\right]_{\mathrm{i}}$ responses in mouse isolated DRG neurons treated with PS $(20 \mu \mathrm{M})$ and $\mathrm{PGE}_{2}(1 \mu \mathrm{M})$. C, Scatter plots representing the relative response amplitudes for control $(n=207), 1 \mu \mathrm{MPGE} 2(n=175)$, and PGE 2 + PTX (200 $\mathrm{ng} / \mathrm{ml} ; n=151)$ treated DRG neurons. Relative responses represent the minimum amplitudes recorded 3-6 min during PS application (corresponding to the time of drug application) expressed as a percentage of the maximum amplitude recorded in the $0-3$ min period. Some reduction in response (Figure legend continues.) 
DRG neurons ( $>50 \%$ inhibition in 97 of 187 cells; Fig. 3B). Treatment with $\mathrm{PGE}_{2}$ significantly reduced the amplitude of PS responses measured in all neurons by $48.4 \pm 2.6 \%$ (Fig. $3 C$ ). Scatter plots of response amplitudes (Fig. $3 C, I$ ) revealed a large inhibition in some neurons and little or no inhibition in other neurons. The effect of $\mathrm{PGE}_{2}$ was unaffected by the overnight incubation of neurons with PTX (200 ng/ml, 18 h) (Fig. 3C). Conversely, PTX (200 ng/ml, $18 \mathrm{~h}$ ) treatment fully reversed morphine-mediated $\mathrm{G}_{\mathrm{i} / \mathrm{o}}$ inhibition of PS-evoked responses in DRG neurons (Fig. 3D-F) (Badheka et al., 2017; Dembla et al., 2017; Quallo et al., 2017). These findings demonstrate that $\mathrm{PGE}_{2}$ inhibits PS responses independently of $G_{i / o}$.

$P_{G}$ acts on two cognate $G_{s}$-coupled $E$ prostanoid receptors, EP2 and EP4, both of which are found in DRG neurons (Cruz Duarte et al., 2012). To determine the relative contribution of these receptors to the $\mathrm{PGE}_{2}$-mediated inhibition of TRPM3, we used the selective EP2 agonist butaprost and the selective EP4 agonist CAY10598. Butaprost $(1 \mu \mathrm{M})$ significantly inhibited PSinduced $\left[\mathrm{Ca}^{2+}\right]_{\mathrm{i}}$ responses in a subpopulation of neurons ( $>50 \%$ inhibition in 90 of 294 cells) (Fig. $3 G$ ), reducing the overall amplitude of PS-evoked responses by $28.1 \pm 1.8 \%$ compared with control experiments (12.8 $\pm 1.4 \%)$ (Fig. $3 H)$. Butaprost ( 1 $\mu \mathrm{M})$ was still able to inhibit PS-evoked responses in neurons treated with PTX (200 ng/ml, $18 \mathrm{~h}$ ) (Fig. $3 H$ ). In contrast to the effect of the EP2 receptor activator, the selective EP4 receptor agonist CAY10598 (30 nM) had no effect on PS responses in DRG neurons compared with untreated controls (Fig. 3I).

TRPM3 is widely expressed in DRG neurons and mediates PS-evoked $\left[\mathrm{Ca}^{2+}\right]_{\mathrm{i}}$ responses (Vriens et al., 2011). Here we found that $64.2 \%$ (52 of 81 ) of DRG neurons studied by voltage-clamp responded to stimulation with PS, which agrees well with previously reported results (Vriens et al., 2011). To confirm that PSevoked currents in DRG neurons were mediated by TRPM3, the selective TRPM3 antagonist ononetin $(10 \mu \mathrm{M})$ (Straub et al., 2013) was applied during PS application. Ononetin inhibited PS evoked currents completely (by $98 \pm 2 \%$ ) and reversibly in all treated cells (Fig. 3J). We therefore conclude that TRPM3 mediates PS-evoked current responses in DRG neurons.

Voltage-clamp recordings confirmed that $\mathrm{PGE}_{2}$ and butaprost inhibited PS-evoked TRPM3 currents in isolated DRG neurons. Application of $\mathrm{PGE}_{2}(1 \mu \mathrm{M})$ or butaprost $(1 \mu \mathrm{M})$ reversibly inhibited PS-evoked TRPM3 currents to a similar extent (by $65.7 \pm$ $10.6 \%$ and $50.5 \pm 8.9 \%$ ) (Fig. $3 K-M$ ). These results demonstrate that activation of $\mathrm{G}_{\mathrm{s}}$-coupled EP2 receptor inhibits TRPM3 in DRG neurons.

$\leftarrow$

(Figure legend continued.) amplitude was typically seen in control conditions. $\boldsymbol{D},\left[\mathrm{Ca}^{2+}\right]_{\mathrm{i}}$ responses in isolated DRG neurons treated with PS $(20 \mu \mathrm{m})$ and morphine $(10 \mu \mathrm{M}) . \boldsymbol{E},\left[\mathrm{Ca}^{2+}\right]_{\mathrm{i}}$ responses in PTX-treated $(200 \mathrm{ng} / \mathrm{mll})$ isolated DRG neurons challenged with PS $(20 \mu \mathrm{M})$ and morphine $(10 \mu \mathrm{M}) . \boldsymbol{F}$, Scatter plot representing the relative amplitudes of control $(94.3 \pm 1.6 \%$ SEM,$n=164),(\boldsymbol{D})(48.4 \pm 2.7 \%$ SEM,$n=109)$, and $(\boldsymbol{E})(86 \pm 2.3 \%$ SEM,$n=135)$ neurons. $\mathbf{G},\left[\mathrm{Ca}^{2+}\right]_{\mathrm{i}}$ responses in isolated mouse DRG neurons treated with PS (20 $\left.\mu \mathrm{m}\right)$ and butaprost (1 $\mu \mathrm{M}) . \boldsymbol{H}$, Scatter plot representing the relative amplitude in control $(n=212)$, butaprost $(n=$ 250), and butaprost + PTX ( $n=140)$ treated DRG neurons. I, Scatter plot representing the relative amplitude in control $(n=409), \mathrm{PGE}_{2}(n=185)$, butaprost $(n=294)$, and CAY10595 $(30 \mathrm{~nm} ; n=207)$ treated DRG neurons. J, Ononetin $(10 \mu \mathrm{M})$ mediated inhibition of PS $(50 \mu \mathrm{M})$ evoked currents in whole-cell voltage-clamp recordings $(60 \mathrm{mV})$ in isolated DRG neurons $(n=$ 6). $K, L$, Example traces of $\mathrm{PGE}_{2}$ and butaprost (both $1 \mu \mathrm{m}$ ) mediated inhibition of PS $(50 \mu \mathrm{M})$ evoked currents in whole-cell voltage-clamp recordings $(60 \mathrm{mV})$ in isolated DRG neurons. $\boldsymbol{M}$, Scatter plot representing PGE2 and butaprost current inhibition of TRPM3-evoked currents inhibition in $(K)(n=6)$ and $(\boldsymbol{L})(n=7)\left(t_{(11)}=1.11, p=0.289\right.$, two-tailed unpaired $t$-test). ${ }^{* * *} p<0.001$ compared with control; ${ }^{\# \#} p<0.001$ compared with morphine-treated cells; Kruskal-Wallis with Dunn's multiple-comparisons test.
A

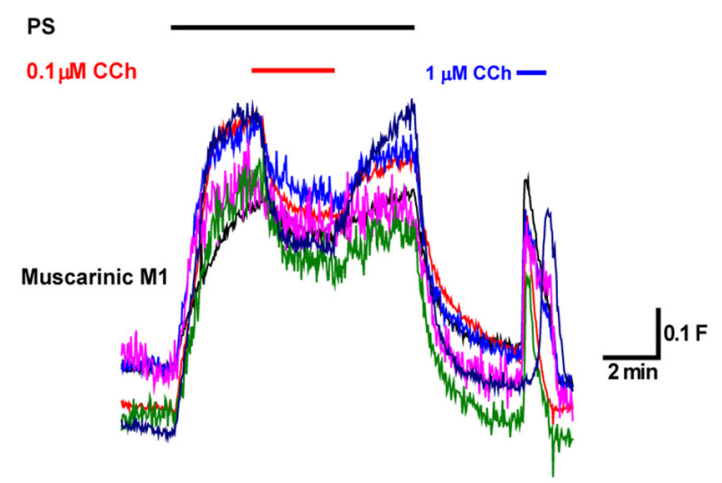

B

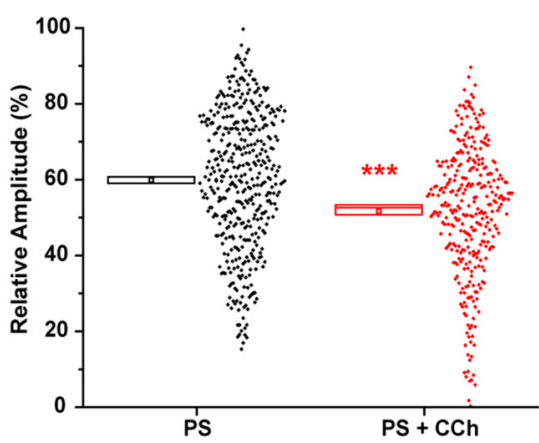

C

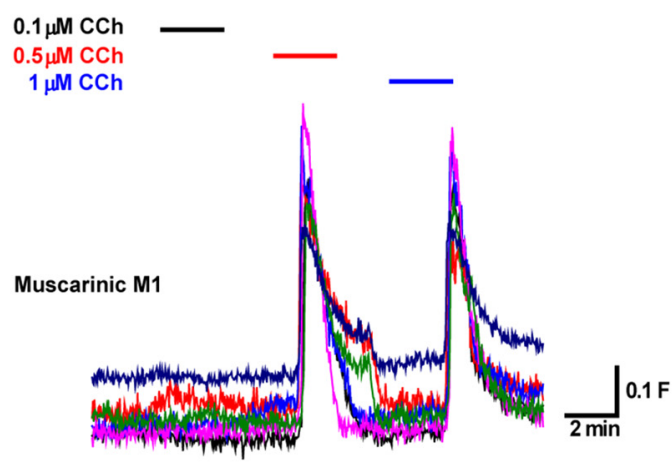

Figure 4. Gq-coupled muscarinic M1 receptor activation inhibits TRPM3-mediated responses in HEK293 cells. $A,\left[\mathrm{Ca}^{2+}\right]_{\mathrm{i}}$ responses in TRPM3/muscarinic M1 HEK293 cells treated with PS $(20 \mu \mathrm{M})$ and carbachol $(0.1 \mu \mathrm{M})$ followed by application of a high concentration of carbachol (1 $\mu \mathrm{M})$ to confirm M1 transfection. $\boldsymbol{B}$, Scatter plot representing the mean, median, and SEM of the relative amplitude from control cells $(60 \pm 0.9 \%$ SEM, $n=431)$ and $(A)$ $(51.7 \pm 1.0 \%$ SEM,$n=329)$, (Mann-Whitney $\left.U=52821, p<10^{-4}\right)$. ${ }^{* *} p<0.001$. C, $\left[\mathrm{Ca}^{2+}\right]_{\mathrm{i}}$ responses in TRPM3/muscarinic M1 HEK293 cells with application of different carbachol concentrations.

\section{$\mathrm{G}_{\mathrm{q}}$-mediated inhibition of TRPM3 in sensory neurons}

It has previously been shown that stimulation of $\mathrm{G}_{\mathrm{q}}$-coupled muscarinic acetylcholine $\mathrm{M} 1$ and $\mathrm{BK} 2$ receptors leads to the inhibition of TRPM3-evoked currents in recombinant cells (Badheka et al., 2017). Consistent with these results, we found that activation of muscarinic M1 receptors inhibited TRPM3mediated $\left[\mathrm{Ca}^{2+}\right]_{\mathrm{i}}$ responses in HEK293 cells (Fig. 4A,B). As M1 receptor activation can increase $\left[\mathrm{Ca}^{2+}\right]_{\mathrm{i}}$, we therefore used a low concentration of carbachol $(0.1 \mu \mathrm{M})$ that did not evoke a $\left[\mathrm{Ca}^{2+}\right]_{\mathrm{i}}$ response in control experiments (Fig. 4C).

We next examined whether $\mathrm{G}_{\mathrm{q}}$-coupled GPCRs can inhibit the activity of TRPM3 in its native environment by stimulating isolated DRG neurons with bradykinin, a pronociceptive media- 
A

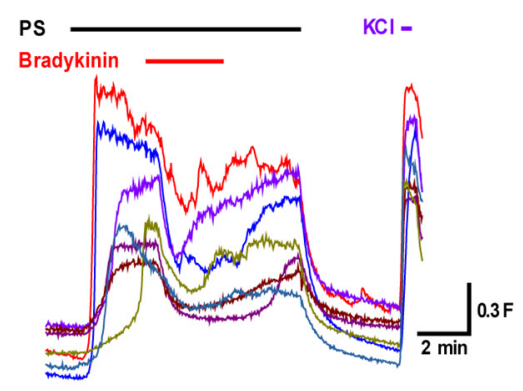

D

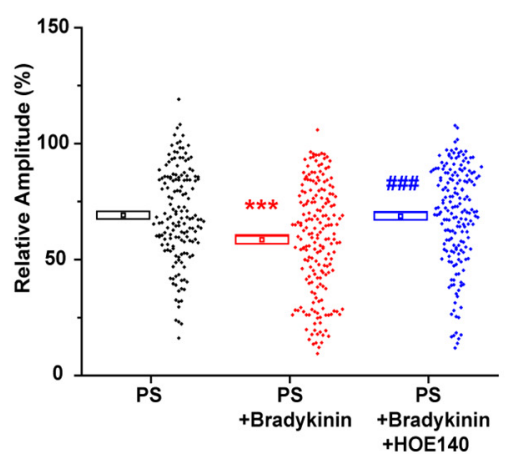

B

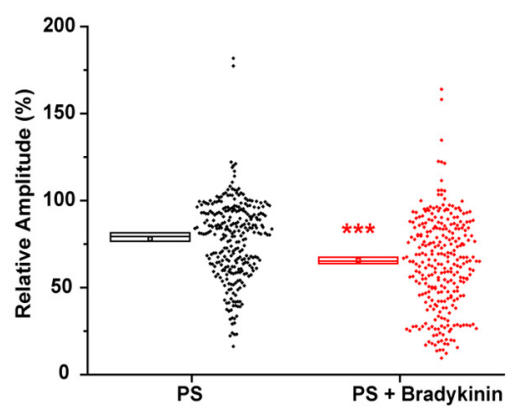

E

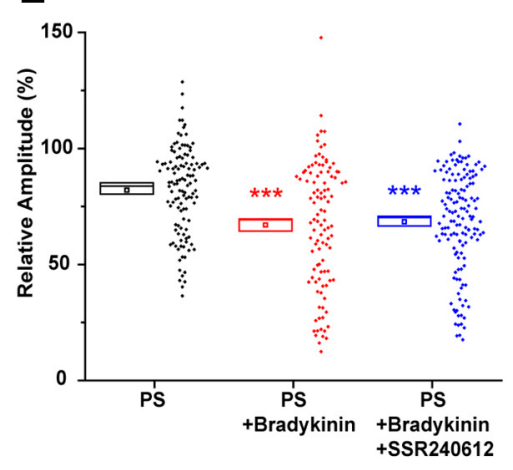

C
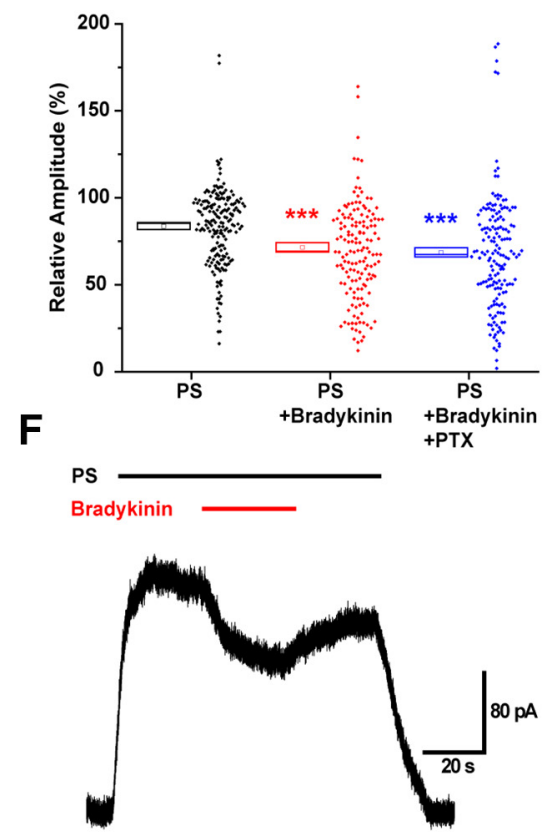

Figure 5. Bradykinin BK2 receptor activation inhibits TRPM3-mediated responses in sensory neurons. $A_{1}\left[\mathrm{Ca}^{2+}\right]_{\mathrm{i}}$ responses in isolated mouse DRG neurons treated with PS (20 $\left.\mu \mathrm{M}\right)$ and bradykinin $(100 \mathrm{~nm}) . \boldsymbol{B}$, Scatter plot representing the relative amplitudes in control $(n=293)$ and bradykinin $(n=293)$ treated DRG neurons (Mann-Whitney $\left.U=29892, p<10^{-4}\right)$. ${ }^{* * *} p<0.001 . C, S c a t t e r$ plot representing the relative amplitudes in control $(n=190)$, bradykinin $(n=157)$, and bradykinin + PTX $(200 \mathrm{ng} / \mathrm{ml} ; n=165)$ treated DRG neurons. D, Scatter plot representing the relative amplitudes in control $(n=157)$, bradykinin $(n=197)$, and bradykinin + HOE $140(50 \mathrm{~nm} ; n=182)$ treated DRG neurons. $\boldsymbol{E}$, Scatter plot representing the relative amplitudes in control $(n=118)$, bradykinin $(n=106)$, and bradykinin + SSR240612 (50 nм; $n=144)$-treated DRG neurons. ${ }^{* * *} p<0.001$ compared with control; ${ }^{\# \#} p<0.001$ compared with bradykinin-treated cells, Kruskal-Wallis with Dunn's multiple-comparisons test $\boldsymbol{C}-\boldsymbol{E}$. $\boldsymbol{F}$, Example trace of bradykinin (100 nм) mediated inhibition of PS (50 $\mu \mathrm{M})$ evoked currents in whole-cell voltage-clamp recordings ( 60 $\mathrm{mV}$ ) in isolated DRG neurons.

tor often used to sensitize nociceptors (Petho and Reeh, 2012). Application of bradykinin (100 nM) strongly, and rapidly inhibited PS-induced $\left[\mathrm{Ca}^{2+}\right]_{\mathrm{i}}$ responses in a subpopulation of DRG neurons ( $>50 \%$ inhibition in 86 of 293 cells) (Fig. $5 A$ ). Bradykinin treatment significantly reduced the amplitude of PS responses by $34.4 \pm 1.4 \%$ compared with control experiments $(22 \pm 1.8 \%$; Fig. $5 B$ ). The effect of bradykinin was unaltered by PTX pretreatment (200 ng/ml, 18 h; Fig. 5C). Furthermore, pretreatment with the selective BK2 receptor antagonist HOE 140 ( $50 \mathrm{nM}$ ) completely prevented the effect of bradykinin (control, reduced by $30.9 \pm 1.6 \%$ from the maximal amplitude; bradykinin: $41.5 \pm 1.7 \%$; bradykinin + HOE 140: $31.3 \pm 1.6 \%$ ) (Fig. $5 D)$. In contrast, the BK1 receptor antagonist SSR240612 (50 nM) was without effect on bradykinin-mediated inhibition of TRPM3 (control: reduced by $17.9 \pm 1.7 \%$; bradykinin: $33.0 \pm 2.6 \%$; bradykinin + SSR240612: $31.6 \pm 1.8 \%$; Fig. $5 E$ ).

We also examined the effects of bradykinin on DRG neurons electrophysiologically. Application of bradykinin (100 nM) to DRG neurons in the voltage-clamp configuration reversibly inhibited PSevoked TRPM3 currents (by $53.7 \pm 10.8 \%$ SEM, $n=5$; Fig. $5 F$ ). Together, these results show that bradykinin inhibits TRPM3 in DRG neurons by activating $\mathrm{G}_{\mathrm{q}}$-coupled BK2 receptors.

\section{$G_{s}-$ and $G_{q}$-mediated inhibition of TRPM3 is independent of PKA and PKC activity}

Canonical $\mathrm{G}_{\mathrm{s}}$ - and $\mathrm{G}_{\mathrm{q}}$-coupled receptor signaling leads to the downstream activation of PKA and PKC. This has been previously shown to increase nociceptor excitability, by sensitizing voltage-gated sodium channels and T-type VGCCs (England et al., 1996; Gold et al., 1998; Kim et al., 2006; Chemin et al., 2007) and the noxious heat transduction channel TRPV1 (Bevan et al., 2014). We used the selective PKA inhibitor KT5720 to determine whether PKA contributed to the EP2-mediated inhibition of TRPM3. The butaprost-induced inhibition of PS-evoked $\left[\mathrm{Ca}^{2+}\right]_{i}$ responses in DRG neurons was unaffected by KT5720 (1 $\mu \mathrm{M})$ (control: $19.3 \pm 1.8 \%$; butaprost: $29.2 \pm 2.6 \%$; butaprost + KT5720:33.3 $\pm 2 \%$; Fig. $6 A, B)$. Conversely, we used the adenylyl cyclase activator forskolin to raise intracellular cAMP and activate PKA. Forskolin $(10 \mu \mathrm{M})$ was applied $6 \mathrm{~min}$ before and during PS and butaprost application. Forskolin treatment did not alter PS-induced $\left[\mathrm{Ca}^{2+}\right]_{\mathrm{i}}$ responses in neurons and had no effect on butaprost-mediated inhibition of PS responses (control: $16.3 \pm$ $1.40 \%$; butaprost: $36.2 \pm 2.15 \%$; forskolin: $13.8 \pm 2.2 \%$; butaprost + forskolin: $35.8 \pm 2.2 \%$; Fig. $6 C, D)$.

We examined whether PKC may be responsible for the inhibition of TRPM3 by BK2 receptor activation by applying the selective $P K C$ inhibitor BIM VIII $(1 \mu \mathrm{M})$ before and during bradykinin application. BIM VIII treatment did not prevent bradykinin-mediated inhibition of PSinduced $\left[\mathrm{Ca}^{2+}\right]_{\mathrm{i}}$ responses in neurons (control: $21.9 \pm 1.2 \%$; bradykinin: $40.9 \pm 1.5 \%$; bradykinin + BIM VIII: $55.9 \pm 1.4 \%$; Fig. $6 E, F$ ). Together, these observations strongly suggest that Gs- and Gq-coupled GPCRs inhibit TRPM3 independently of cAMP, PKA, and PKC.

\section{G $\boldsymbol{\beta} \gamma$ subunits mediate inhibition of TRPM3 in heterologous and endogenous systems}

Because the major canonical signaling events activated by $\mathrm{G} \alpha$ s and $\mathrm{G} \alpha$ q did not affect TRPM3 inhibition, we next examined the potential involvement of G $\beta \gamma$ protein. TRPM3 HEK293 cells 
A

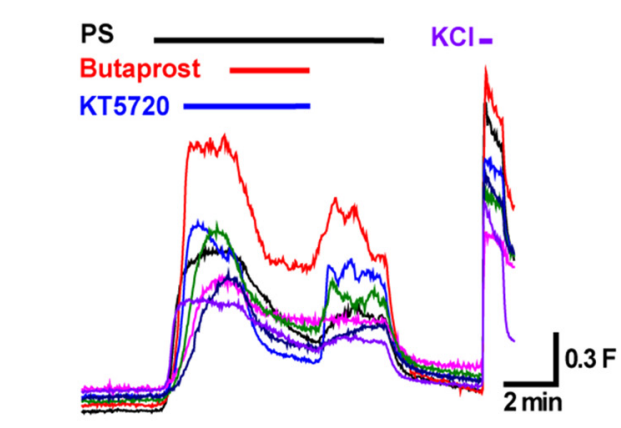

C

\section{PS}

Butaprost

E

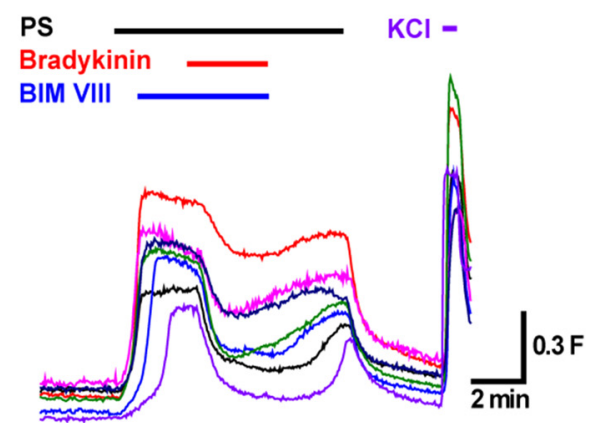

B
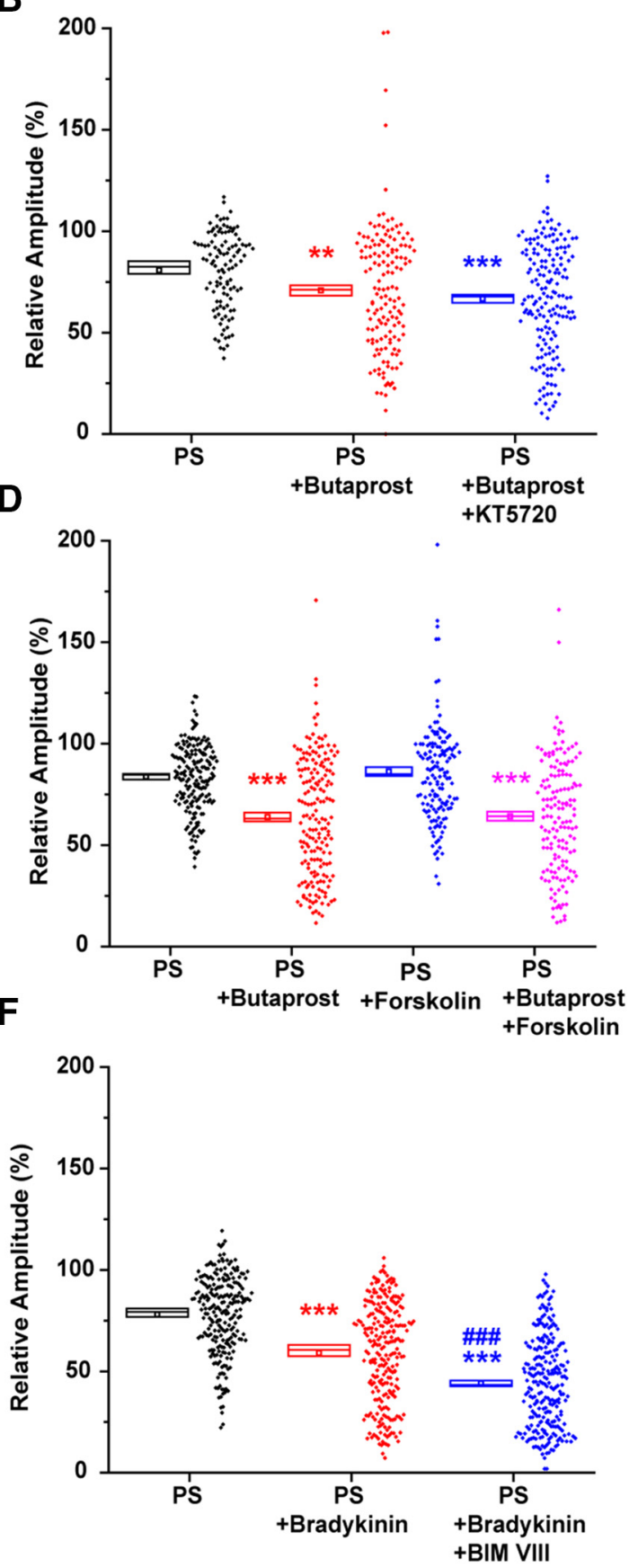

Figure 6. $\mathrm{G}_{\mathrm{s}}$ - and $\mathrm{G}_{\mathrm{q}}$-coupled mediated inhibition of TRPM3 is independent of PKA and PKC activity. $A,\left[\mathrm{Ca}^{2+}\right]_{\mathrm{i}}$ responses in isolated mouse DRG neurons treated with PS (20 $\left.\mu \mathrm{M}\right)$, butaprost (1 $\mu \mathrm{M})$, and KT5720 $(1 \mu \mathrm{M})$. B, Scatter plot representing the relative amplitudes in control $(n=112)$, butaprost-treated $(n=151)$, and butaprost $+\mathrm{KT} 5720$-treated $(n=151)$ cells. $C$, $\left[C^{2+}\right]_{i}$ responses in isolated mouse DRG neurons treated with PS $(20 \mu \mathrm{M})$, butaprost $(1 \mu \mathrm{M})$, and forskolin $(10 \mu \mathrm{M})$. $\boldsymbol{D}$, Scatter plot representing the relative amplitudes in control $(n=185)$, butaprosttreated $(n=183)$, forskolin-treated $(n=148)$, and butaprost + forskolin-treated $(n=155)$ cells. $E$, $\left[\mathrm{Ca}^{2+}\right]_{\mathrm{i}}$ responses in isolated mouse DRG neurons treated with PS (20 $\left.\mu \mathrm{M}\right)$, bradykinin $(100$ $\mathrm{nM})$, and BIM VIII $(1 \mu \mathrm{M}) . \boldsymbol{F}$, Scatter plot representing the relative amplitudes in control $(n=236)$, bradykinin-treated $(n=257)$, and bradykinin + BIM VIII-treated $(n=248)$ cells. ${ }^{* *} p=0.0014$; ${ }^{* * *} p<0.001$ compared with control; ${ }^{\# \# \#} p<0.001$ compared with bradykinin-treated cells; Kruskal-Wallis with Dunn's multiple-comparisons test.

were transiently transfected with the $\mathrm{G} \beta \gamma \operatorname{sink} \beta \mathrm{ARK} 1$-ct ( $\mathrm{C}$ terminus of the $\beta$-adrenergic receptor kinase-1) (Koch et al., 1994) and the effects of A2B activation on TRPM3 examined using $\left[\mathrm{Ca}^{2+}\right]_{\mathrm{i}}$ measurements. $\beta$ ARK1-ct transfection abolished the inhibitory effect of adenosine $(100 \mu \mathrm{M})$ and BAY $60-6583(20 \mu \mathrm{M})$ application on TRPM3-mediated responses compared with untransfected cells (control: $83.7 \pm 1.40 \%$; adenosine: $34.2 \pm 1.1 \%$; adenosine $+\beta$ ARK1-ct: $75.3 \pm 0.8 \%$; BAY 60-6583: $64.1 \pm$ $0.5 \%$; and BAY $60-6583+\beta$ ARK1-ct: $80.5 \pm 0.6 \%)$. Similarly,
TRPM3 inhibition by muscarinic M1 receptor activation was completely prevented by transfection with $\beta$ ARK1-ct (control: $59.9 \pm 0.86 \%$; carbachol: $51.7 \pm 0.95 \%$; and carbachol + $\beta A R K 1-c t: 60.3 \pm 0.84 \%$; Fig. $7 A-F)$. To confirm the involvement of G beta-gamma, we also used GRK2i, a smaller 28 amino acid polypeptide that corresponds to the $G \beta \gamma$ binding region of $\beta$ ARK1 ( $\beta$-adrenoreceptor kinase 1 also known as GRK2, G-protein receptor kinase 2). GRK2i (10 $\mu \mathrm{M})$ dialysis of TRPM3 HEK293 cells in the whole-cell recording configuration for $>5 \mathrm{~min}$ 
A
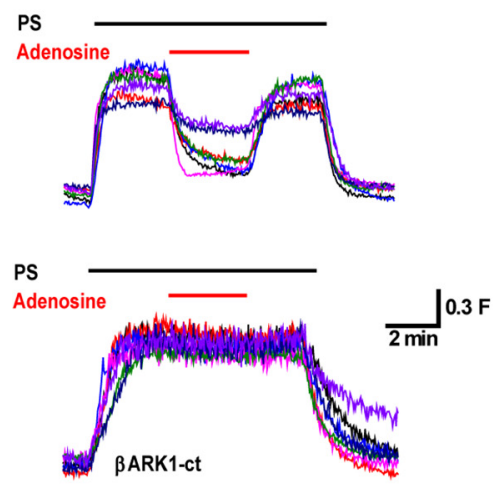

D
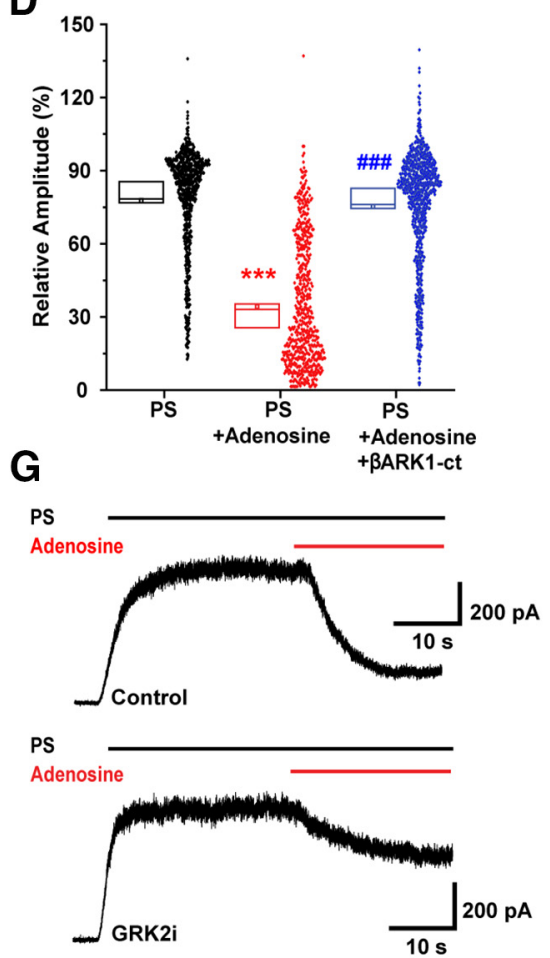

J

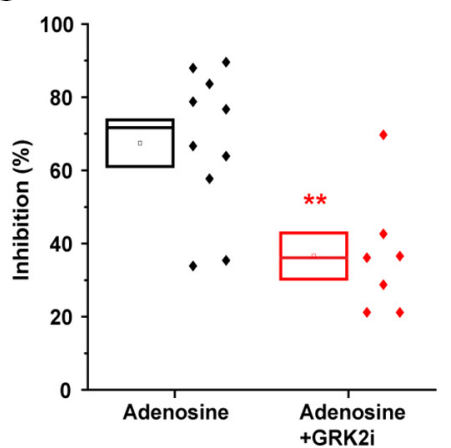

B

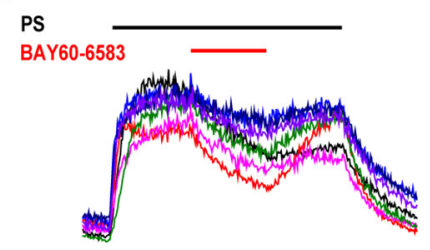

PS

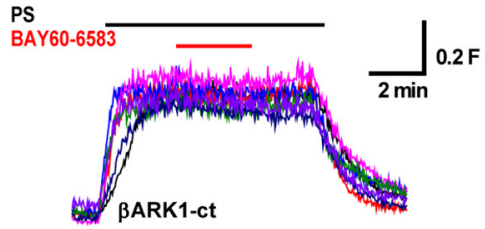

E

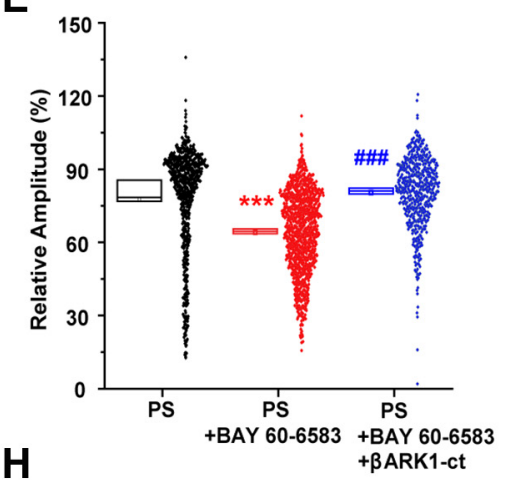

PS

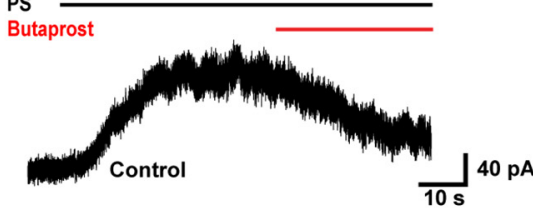

PS

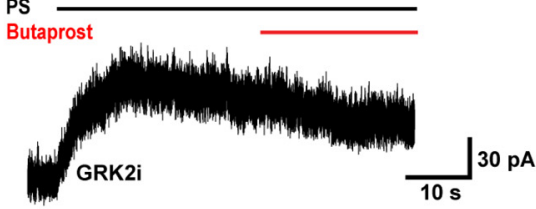

K

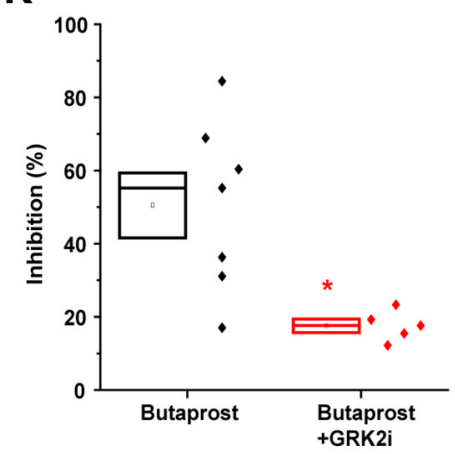

C
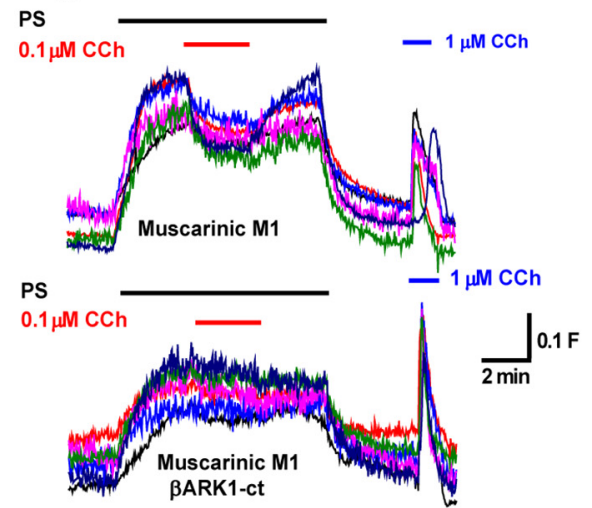

F
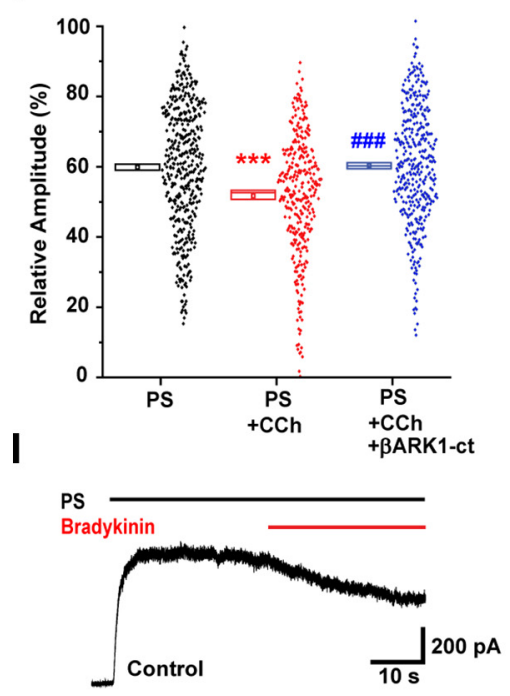

PS

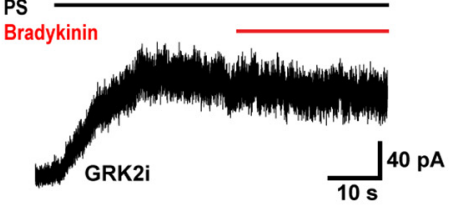

L

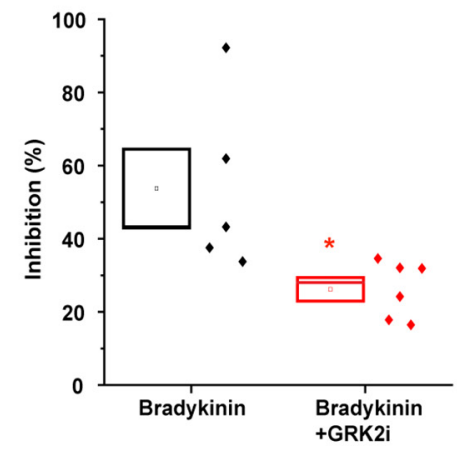

Figure 7. $\mathrm{G}_{\mathrm{s}}$ - and $\mathrm{G}_{\mathrm{q}}$-coupled $\mathrm{GPCR}$ inhibition of TRPM 3 is reliant on $\mathrm{G} \beta \gamma$ protein. $\boldsymbol{A}-\mathrm{C}_{\mathrm{f}}\left[\mathrm{Ca}^{2+}\right]_{\mathrm{i}}$ responses in control (top) and $\beta$ ARK1-ct transfected (bottom) TRPM3 HEK293 cells treated with PS (20 $\mu \mathrm{M}$ ) and adenosine (100 $\mu \mathrm{M}, n=852)$, BAY $60-6583(20 \mu \mathrm{M}, n=553)$, or carbachol $(0.1 \mu \mathrm{M}, n=386)$. D- $\boldsymbol{F}$, Scatter plots representing the relative amplitudes of $\boldsymbol{A}-\boldsymbol{C}$ with $\beta$ ARK1-ct untransfected control and treated TRPM3 HEK293 cells. ${ }^{* * *} p<0.001$ compared with control; ${ }^{\# \#} p<0.001$ compared with treated cells; Kruskal-Wallis with Dunn's multiple-comparisons test. G-I, Example traces of adenosine $(100 \mu \mathrm{m})$, butaprost $(1 \mu \mathrm{m})$, and bradykinin ( $100 \mathrm{~nm})$ mediated inhibition of PS (100 $\mu \mathrm{m}$ for HEK cells and $50 \mu \mathrm{m}$ for DRG neurons)-evoked currents in whole-cell voltage-clamp recordings ( $+60 \mathrm{mV}$ ) in HEK293 cells (for adenosine) and isolated DRG neurons (for butaprost and bradykinin) in control (top) and GRK2i (10 $\mu \mathrm{M}$, bottom) intracellular solutions. J-L, Scatter plots representing TRPM3-evoked current inhibition in $(\boldsymbol{G})\left(t_{(15)}=3.32, p=0.0047\right.$, control $n=10$, GRK2i $n=7$, two-tailed unpaired $t$-test), $(\boldsymbol{H})\left(t_{(10)}=3.06, p=0.012\right.$, control $n=$ 7, GRK2i $n=5$, two-tailed unpaired $t$-test), and $(\boldsymbol{L})\left(t_{(9)}=2.67, p=0.026\right.$, control: $n=5$, GRK2i: $n=6$, two-tailed unpaired $t$-test). ${ }^{*} p<0.05$. ${ }^{* *} p<0.01$. 
A

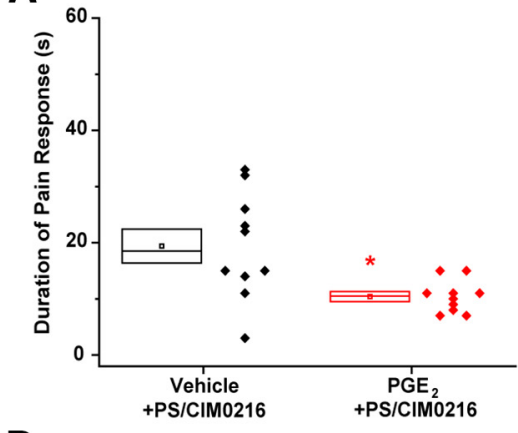

D

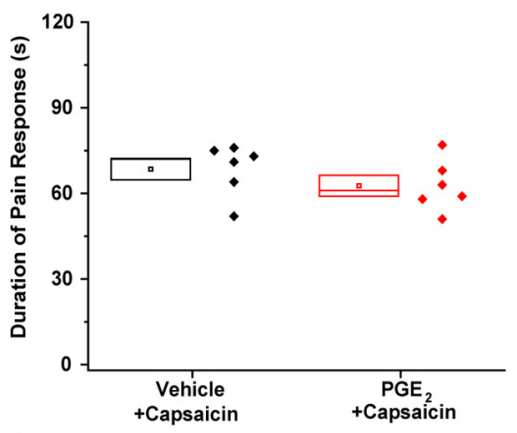

G

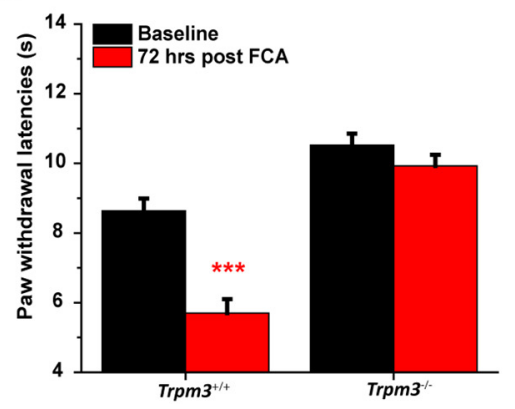

B

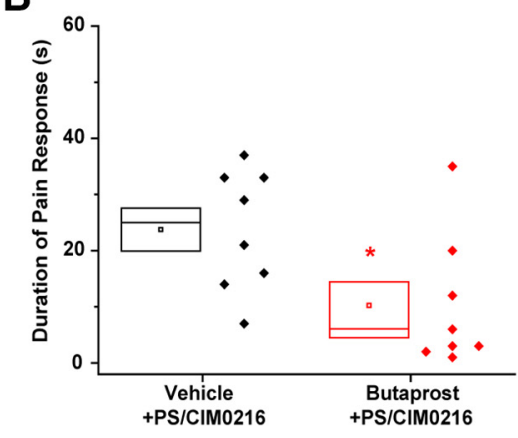

E

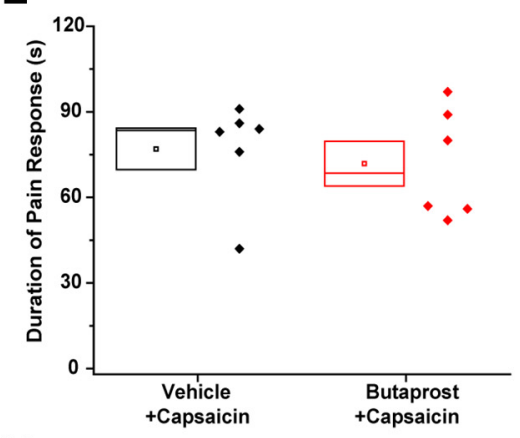

H

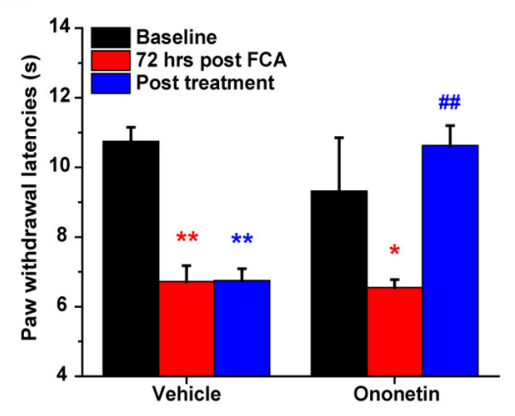

C

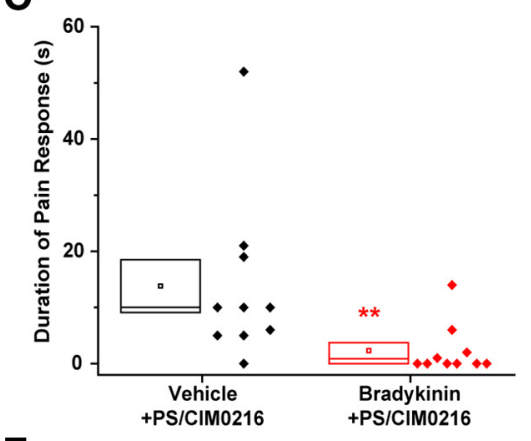

F

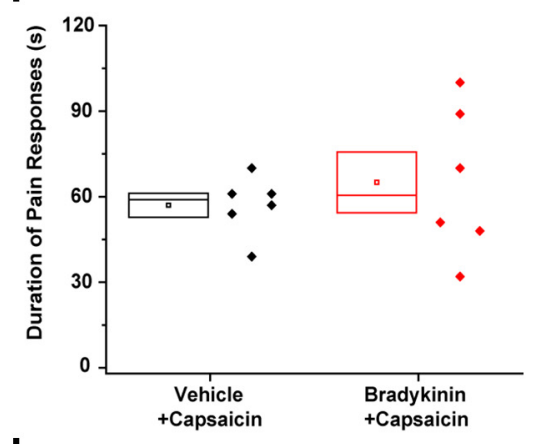

|

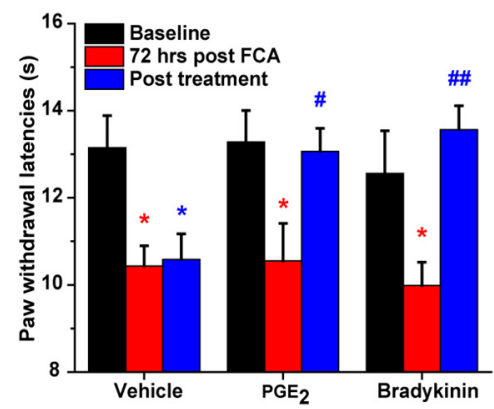

Figure 8. $\quad G_{s}$ - and $G_{q}$-coupled GPCR activation prevents mouse nociceptive behavior in response to TRPM3 agonists and reverses heat hyperalgesia in FCA-treated mice. $\boldsymbol{A}$ - $\boldsymbol{C}$, Scatter plots representing the duration of pain responses in mice with intraplantar hindpaw injections of $\operatorname{PGE}_{2}\left(t_{(18)}=2.86, p=0.0103, n=10\right.$, two-tailed unpaired $t$-test), butaprost (Mann-Whitney $U=$ $10.5 ; p=0.0258, n=8$, two-tailed), and bradykinin (Mann-Whitney $U=15.5, p=0.0062, n=10$, two tailed) (all at a dose of $0.3 \mathrm{nmol}$ ) or with vehicle before PS ( $5 \mathrm{nmol}$ ) $/ \mathrm{CIM0216}$ ( $0.5 \mathrm{nmol}$ ) administration. ${ }^{*} p<0.05 ;{ }^{* *} p<0.01 . D-F$, Scatter plots representing the duration of pain responses in mice administered with intraplantar hindpaw injections of $P G E_{2}\left(t_{(10)}=1.11, p=0.29\right.$, two-tailed unpaired $t$-test), butaprost (Man-Whitney $\mathrm{U}=16, p=0.82$, two-tailed), and bradykinin $\left(t_{(10)}=0.69, p=0.5\right.$, two-tailed unpaired $t$-test) $(0.3 \mathrm{nmol}, n=6$, all) or with vehicle before capsaicin ( $5 \mathrm{nmol}$ ) administration. G, Bar chart comparing heat withdrawal latencies of mice from $50^{\circ} \mathrm{C}$ hotplate before and $72 \mathrm{~h}$ after intraplantar FCA $(15 \mu l)$ injection in Trpm $3^{+/+}\left(t_{(14)}=5.49\right.$, $p<0.0001$, two-tailed unpaired $t$-test) and Trpm3 ${ }^{-/-}$mice $\left(t_{(14)}=1.31, p=0.21\right.$, two-tailed unpaired $t$-test) $(n=8 \text {, both })^{* * *} p<0.001$. $\boldsymbol{H}$, Bar chart comparing heat withdrawal latencies of mice from $50^{\circ} \mathrm{C}$ hotplate before and $72 \mathrm{~h}$ after injection with FCA $(15 \mu \mathrm{l})$, vehicle or ononetin $\left(10 \mathrm{mg} / \mathrm{kg} ; F_{(2,30)}=7.2, p=0.0028\right)$ application $(n=6$, both). $I$, Bar chart comparing heat withdrawal latencies of mice from $50^{\circ} \mathrm{C}$ hotplate before and $72 \mathrm{~h}$ after injection with $\mathrm{FCA}(15 \mu \mathrm{l})$ or vehicle, $\mathrm{PGE}_{2}\left(0.3 \mathrm{nmol} ; F_{(2,30)}=4.7, p=0.0168\right)$, or bradykinin $\left(0.3 \mathrm{nmol} ; F_{(2,30)}=6.21, p=\right.$ $0.0055)$ ( $n=6$, each). ${ }^{*} p<0.05 ;{ }^{* *} p<0.01$, compared with baseline; ${ }^{*} p<0.05$; \#\# $p<0.01$, compared with 72 h after FCA; two-way ANOVA followed by Tukey's multiple-comparisons test.

significantly reduced adenosine-mediated inhibition of TRPM3evoked currents (control: $67.4 \pm 6.4 \%$; GRK2i: $36.6 \pm 6.3 \%$ ). We next examined the involvement of G $\beta \gamma$ in EP2- and BK2mediated inhibition of TRPM3 by dialyzing GRK2i in isolated DRG neurons. GRK2i (10 $\mu \mathrm{M})$ dialysis significantly reduced the butaprost- and bradykinin-mediated inhibition of TRPM3evoked currents (butaprost: $50.5 \pm 8.9 \%$; GRK2i and butaprost: $17.6 \pm 1.9 \%$; bradykinin: $53.7 \pm 10.8 \%$; and GRK2i and bradykinin: $26.2 \pm 3.2 \%$; Fig. $7 G-L$ ). These results demonstrate that G $\beta \gamma$ subunits are responsible for TRPM3 inhibition produced by activation of GPCRs coupled to $\mathrm{G} \alpha_{\mathrm{s}}$ and $\mathrm{G} \alpha$ in heterologous and native cell systems.

$\mathrm{G}_{\mathrm{s}}$ - and $\mathrm{G}_{\mathrm{q}}$-coupled GPCRs inhibit TRPM3-mediated nociception As activation of EP2 and BK2 receptors inhibits TRPM3 in isolated DRG neurons, we next examined whether activation of EP2 and BK2 receptors can inhibit pain evoked by TRPM3 agonists in vivo. Previous studies in Trpm $3^{-1-}$ mice showed that the behavioral nocifensive responses to intraplantar injections of PS and a second TRPM3 agonist CIM0216 are dependent on TRPM3 (Held et al., 2015). Intraplantar administration of a combination of $5 \mathrm{nmol}$ PS and $0.5 \mathrm{nmol}$ CIM0216 evoked a robust paw licking/ flinching behavior in WT mice. Intraplantar administration of $0.3 \mathrm{nmol}$ of $\mathrm{PGE}_{2}$ (10 min before), butaprost (10 min before), or bradykinin ( 5 min before) before PS/CIM0216 administration, significantly reduced the pain-related paw licking and flicking behavioral responses evoked by the TRPM3 agonists (Fig. 8A-C). The doses of $\mathrm{PGE}_{2}$, butaprost, and bradykinin were chosen not to directly evoke pain-related behavioral responses.

To test whether this effect is specific for TRPM3-dependent nociception, we examined whether activation of EP2 and BK2 
receptors could also inhibit TRPV1-mediated behavioral responses because many TRPM3 expressing neurons also express TRPV1 (Vriens et al., 2011). However, neither PGE 2 (vehicle: $68.5 \pm 3.7 \mathrm{~s} ; \mathrm{PGE}_{2}: 62.7 \pm 3.7 \mathrm{~s}$ ), nor butaprost (vehicle: $77 \pm$ $7.3 \mathrm{~s}$; butaprost: $72 \pm 7.9 \mathrm{~s}$ ), nor bradykinin (vehicle: $57 \pm 4.2 \mathrm{~s}$; bradykinin: $65 \pm 10.7 \mathrm{~s}$ ) inhibited capsaicin-evoked behaviors (Fig. $8 D-F$ ), in marked contrast to their inhibitory effect on responses elicited by PS/CIM0216.

TRPM3 is required for the development and maintenance of inflammatory heat hyperalgesia, which consequently has been found to be absent from Trpm3 $3^{-/-}$mice (Vriens et al., 2011). We compared the heat sensitivity of $\operatorname{Trpm} 3^{+/+}$and $\operatorname{Trpm} 3^{-/-}$mice $3 \mathrm{~d}$ after intraplantar injections of Freund's complete adjuvant (FCA, $15 \mu \mathrm{l}$ ). FCA reduced the paw withdrawal latency in WT mice in the hotplate test $\left(50^{\circ} \mathrm{C}\right)$ but was without effect in $\operatorname{Trpm} 3^{-/-}$mice, in good agreement with earlier observations (Vriens et al., 2011), indicating that TRPM3 is of critical importance for inflammatory heat hypersensitivity (Fig. 8G). Administration of the selective TRPM3 inhibitor ononetin (10 mg/kg, i.p.) completely reversed established FCA-induced heat hypersensitivity (Fig. $8 \mathrm{H}$ ), demonstrating that the loss of hypersensitivity in $\operatorname{Trpm} 3^{-/-}$mice was unlikely to be caused by developmental or compensatory mechanisms and suggests that TRPM3 may be a tractable target for inflammatory pain.

FCA has long been used as a model for inflammatory hypersensitivity and pain, but the precise mechanisms by which it produces pain and hypersensitivity are not known. To determine the influence of local, intraplantar injections of $\mathrm{PGE}_{2}$ and bradykinin on established FCA-induced heat hyperalgesia, we administered the same doses that inhibited the behavioral response to TRPM3 agonists (Fig. $8 \mathrm{~A}, \mathrm{C}$ ) but did not evoke a behavioral response on their own (5 or 10 min before hotplate test). Perhaps counterintuitively, intraplantar administration of either $\mathrm{PGE}_{2}$ or bradykinin fully reversed heat hyperalgesia in FCA-treated mice (Fig. $8 I$ ). These observations are consistent with our observations that EP2 and BK2 receptor activation inhibit TRPM3 in vitro and mimic the effects of pharmacological blockade or genetic inactivation of TRPM3 on heat hypersensitivity.

\section{Discussion}

Our results demonstrate, for the first time, that TRPM3 is inhibited by activation of GPCRs coupled to any of the three major classes of $\mathrm{G} \alpha$ in heterologous and native cellular environments. Based on our findings with GDP $\beta$ S-treated cells, we show that TRPM3 is tonically inhibited by G-proteins in HEK293 cells, in good agreement with the tonic inhibition of TRPM3 previously observed in DRG neurons and in vivo (Quallo et al., 2017). Here we show that stimulation of $\mathrm{G}_{\mathrm{s}}$-coupled GPCRs exerts an inhibitory effect on TRPM3 in HEK293 cells and DRG neurons. This inhibition is PTX-insensitive, demonstrating that $\mathrm{G}_{\mathrm{i} / \mathrm{o}}$ is not responsible. Furthermore, the inhibition is not mediated by the canonical signaling pathways engaged by $\mathrm{G}_{\mathrm{s}}$ activation because it is unaffected by PKA inhibition or by stimulation of cAMP production. In contrast, $\mathrm{G}_{\mathrm{s}}$-coupled GPCR inhibition of TRPM3 is fully prevented by expression of $\beta$ ARK1-ct in HEK293 cells, demonstrating that $\mathrm{G} \beta \gamma$ protein is responsible for this inhibition.

Previous investigations demonstrated that $\mathrm{G} \alpha$ does not coimmunoprecipitate with TRPM3 (Dembla et al., 2017) and that inhibition of TRPM3 by heterologous expression of $\mathrm{G}_{\mathrm{q}}$-coupled muscarinic $\mathrm{M} 1$ and $\mathrm{BK} 2$ receptors is unaffected by $\operatorname{PtdIns}(4,5) \mathrm{P}_{2}$ supplementation but is reduced by $\beta A R K 1-c t$ (Badheka et al., 2017). Here, we confirmed these findings by showing that TRPM3-mediated $\left[\mathrm{Ca}^{2+}\right]_{\mathrm{i}}$ responses in HEK293 cells is inhibited by muscarinic M1 receptor activation and that this inhibition is prevented by expression of $\beta A R K 1-c t$, and we have further shown that BK2 receptor activation inhibits TRPM3 in vivo and in isolated DRG neurons. This inhibition is mediated by $\mathrm{G} \beta \gamma$ and is independent of PKC. Along with our observations that $\beta A R K 1-c t$ and GRK2i reversed TRPM3 inhibition by A2B and EP2 activation, these results clearly demonstrate that $\mathrm{G} \beta \gamma$ mediates $\mathrm{G}_{\mathrm{i} / \mathrm{o}^{-}}, \mathrm{G}_{\mathrm{s}^{-}}$, and $\mathrm{G}_{\mathrm{q}}$-induced inhibition of TRPM3.

$\mathrm{G} \beta \gamma$ proteins directly modulate $\mathrm{N}$ - and P/Q-type VGCCs and GIRK channels independently of $\mathrm{G} \alpha$ and regardless of whether they are liberated from $\mathrm{G} \alpha_{\mathrm{i} / \mathrm{o}}, \mathrm{G} \alpha_{\mathrm{s}}$, or $\mathrm{G} \alpha_{\mathrm{q}}$ (for review, see Dascal, 1997; Yamada et al., 1998; Dolphin, 2003). Our results with GTP $\gamma \mathrm{S}$ in control and PTX-treated TRPM3 HEK293 cells show that, although PS-evoked currents were gradually inhibited after PTX treatment, the inhibition developed more quickly in the absence of PTX. A more effective inhibition of TRPM3 by $\mathrm{G}_{\mathrm{i} / \mathrm{o}}$ coupled GPCRs is supported by the stronger inhibition observed following activation of $\mu$-opioid, NPY, and $\mathrm{GABA}_{\mathrm{B}}$ receptors (Quallo et al., 2017) than with $\mathrm{G}_{\mathrm{s}}$ - or $\mathrm{G}_{\mathrm{q}}$-coupled receptors. This finding agrees with the dominant modulation of VGCCs and GIRK channels by activating $\mathrm{G}_{\mathrm{i} / \mathrm{o}}$-coupled GPCRs (Dolphin, 2003). Promiscuous GPCR activation of GIRK channels by G $\beta \gamma$ has been observed, but primarily in heterologous overexpression systems. In sinoatrial node pacemaker cells, GIRK is preferentially activated by the $\mathrm{G}_{\mathrm{i} / \mathrm{o}}$-coupled $\mathrm{M} 2$ muscarinic receptor rather than by the $\mathrm{G}_{\mathrm{s}}$-coupled $\beta 2$-adrenergic receptor (Hein et al., 2006; Digby et al., 2008; Touhara and MacKinnon, 2018). Reports that $\mathrm{G} \beta \gamma$ proteins dissociate more readily from $\mathrm{G} \alpha_{\mathrm{o}}$ than from $\mathrm{G} \alpha_{\mathrm{s}}$ (Digby et al., 2008) lend further support to the notion that $\mathrm{G}_{\mathrm{i} / \mathrm{o}}$-coupled $\mathrm{G} \beta \gamma$ is more effective at inhibiting TRPM3.

The proinflammatory mediators $\mathrm{PGE}_{2}$ and bradykinin are both thought to produce pain and hypersensitivity at least in part by sensitization of sensory neuron TRP channels, such as TRPA1 and TRPV1, downstream of EP2 and BK2 receptors (for review, see Bautista et al., 2013; Veldhuis et al., 2015). Here, low doses of $\mathrm{PGE}_{2}$ and bradykinin that did not evoke a behavioral response on their own significantly reduced the pain-related behavioral responses evoked by topical injections of a combination of the TRPM3 agonists PS and CIM0216, in a manner similar to that observed with application of agonists of the $\mathrm{G}_{\mathrm{i} / \mathrm{o}}$-coupled $\mu$ opioid receptor (Badheka et al., 2017; Dembla et al., 2017; Quallo et al., 2017). This effect appears to be specific for TRPM3 because pain-related behaviors produced by the TRPV1 agonist capsaicin were not inhibited by application of $\mathrm{PGE}_{2}$, butaprost, and bradykinin. Thus, activation of EP2 and $\mathrm{BK} 2$ receptors is unlikely to inhibit pain produced by TRPM3 agonists by interfering with action potential generation or membrane excitability because many TRPM3 expressing neurons also express TRPV1 (Vriens et al., 2011).

We evaluated the effects of $\mathrm{PGE}_{2}$ and bradykinin on heat hypersensitivity produced by intraplantar FCA. The roles of $\mathrm{PGE}_{2}$ and bradykinin in adjuvant-induced hypersensitivity are not clear and the behavioral effects produced by FCA are, for example, unchanged in mice lacking both $\mathrm{BK} 1$ and $\mathrm{BK} 2$ bradykinin receptors (Cayla et al., 2012). Intra-articular injections of FCA in the rat produced mechanical hyperalgesia, which was unaffected by inhibition of BK2 receptors $3 \mathrm{~d}$ after FCA induction, whereas coadministration of a BK2 antagonist together with FCA prevented the development of hypersensitivity, suggesting a role for BK2 in the development, rather than maintenance of hypersensitivity (Perkins et al., 1993). An evaluation of the efficacy of analgesic drugs in rats treated with intraplantar FCA demonstrated that the nonselective NSAIDs indomethacin and diclofenac, at doses that would completely prevent cycloo- 
xygenase-mediated $\mathrm{PGE}_{2}$ formation, produced no, or only a minor reduction of heat hypersensitivity (Nagakura et al., 2003). Here, we found that FCA failed to produce heat hypersensitivity in Trpm $3^{-/-}$mice, and that a selective TRPM3 antagonist, ononetin, produced a complete reversal of the behavioral sensitization produced by FCA in WT mice. Surprisingly, local intraplantar injections of either of the proinflammatory mediators $\mathrm{PGE}_{2}$ or bradykinin also produced a complete reversal of the established FCA-induced heat hypersensitivity in WT mice. Together, our behavioral analysis thus confirms that TRPM3 is critically important for inflammatory heat hyperalgesia (see Vriens et al., 2011), and strongly indicates that activation of GPCRs may produce analgesia by inhibiting TRPM3. Somewhat surprisingly, this was the case following local administration of $\mathrm{PGE}_{2}$ and bradykinin. These latter findings are consistent with the absence of high concentrations of $\mathrm{PGE}_{2}$ and bradykinin in the inflamed paw at this post-FCA time point.

Our results demonstrate that TRPM3 is promiscuously inhibited by $G \beta \gamma$ after activation of receptors coupled to any of the major classes of G-proteins and thus may act as a pan-GPCR effector molecule. We show that $\mathrm{G}_{\mathrm{s}}$ - and $\mathrm{G}_{\mathrm{q}}$-coupled GPCRs inhibit TRPM3 in cell lines and in isolated sensory neurons in vitro and that they can produce antinociception and analgesia by inhibiting TRPM3 in vivo.

\section{References}

Andersson DA, Gentry C, Alenmyr L, Killander D, Lewis SE, Andersson A, Bucher B, Galzi JL, Sterner O, Bevan S, Högestätt ED, Zygmunt PM (2011) TRPA1 mediates spinal antinociception induced by acetaminophen and the cannabinoid $\Delta(9)$-tetrahydrocannabiorcol. Nat Commun 2:551.

Badheka D, Yudin Y, Borbiro I, Hartle CM, Yazici A, Mirshahi T, Rohacs T (2017) Inhibition of transient receptor potential melastatin 3 ion channels by G-protein $\beta \gamma$ subunits. eLife 6:e26147.

Bautista DM, Pellegrino M, Tsunozaki M (2013) TRPA1: a gatekeeper for inflammation. Annu Rev Physiol 75:181-200.

Bevan S, Winter J (1995) Nerve growth factor (NGF) differentially regulates the chemosensitivity of adult rat cultured sensory neurons. J Neurosci 15:4918-4926.

Bevan S, Quallo T, Andersson DA (2014) TRPV1. In: Mammalian transient receptor potential (TRP) cation channels: Vol I. Handbook of experimental pharmacology (Nilius B, Flockerzi V, eds), pp 207-245. Berlin: Springer.

Binkowski B, Fan F, Wood K (2009) Engineered luciferases for molecular sensing in living cells. Curr Opin Biotechnol 20:14-18.

Cayla C, Labuz D, Machelska H, Bader M, Schäfer M, Stein C (2012) Impaired nociception and peripheral opioid antinociception in mice lacking both kinin B1 and B2 receptors. Anesthesiology 116:448-457.

Chemin J, Mezghrani A, Bidaud I, Dupasquier S, Marger F, Barrère C, Nargeot J, Lory P (2007) Temperature-dependent modulation of CaV3 T-type calcium channels by protein kinases $\mathrm{C}$ and $\mathrm{A}$ in mammalian cells. J Biol Chem 282:32710-32718.

Cooper J, Hill SJ, Alexander SP (1997) An endogenous A2B adenosine receptor coupled to cyclic AMP generation in human embryonic kidney (HEK 293) cells. Br J Pharmacol 122:546-550.

Cruz Duarte P, St-Jacques B, Ma W (2012) Prostaglandin E2 contributes to the synthesis of brain-derived neurotrophic factor in primary sensory neuron in ganglion explant cultures and in a neuropathic pain model. Exp Neurol 234:466-481.

Dascal N (1997) Signalling via the G protein-activated $\mathrm{K}^{+}$channels. Cell Signal 9:551-573.

Dembla S, Behrendt M, Mohr F, Goecke C, Sondermann J, Schneider FM, Schmidt M, Stab J, Enzeroth R, Leitner MG, Nuñez-Badinez P, Schwenk J, Nürnberg B, Cohen A, Philipp SE, Greffrath W, Bünemann M, Oliver D, Zakharian E, Schmidt M, et al. (2017) Anti-nociceptive action of peripheral mu-opioid receptors by G-beta-gamma protein-mediated inhibition of TRPM3 channels. eLife 6:e26280.
Digby GJ, Sethi PR, Lambert NA (2008) Differential dissociation of G protein heterotrimers. J Physiol 586:3325-3335.

Dolphin AC (2003) G protein modulation of voltage-gated calcium channels. Pharmacol Rev 55:607-627.

England S, Bevan S, Docherty RJ (1996) PGE2 modulates the tetrodotoxinresistant sodium current in neonatal rat dorsal root ganglion neurones via the cyclic AMP-protein kinase A cascade. J Physiol 495:429-440.

Gold MS, Levine JD, Correa AM (1998) Modulation of TTX-R INa by PKC and PKA and their role in PGE2-induced sensitization of rat sensory neurons in vitro. J Neurosci 18:10345-10355.

Goulding J, May LT, Hill SJ (2018) Characterisation of endogenous A2A and $\mathrm{A} 2 \mathrm{~B}$ receptor-mediated cyclic AMP responses in HEK 293 cells using the GloSensor biosensor: evidence for an allosteric mechanism of action for the A2B-selective antagonist PSB 603. Biochem Pharmacol 147:55-66.

Hein P, Rochais F, Hoffmann C, Dorsch S, Nikolaev VO, Engelhardt S, Berlot CH, Lohse MJ, Bünemann M (2006) Gs activation is time-limiting in initiating receptor-mediated signaling. J Biol Chem 281:33345-33351.

Held K, Kichko T, De Clercq K, Klaassen H, Van Bree R, Vanherck JC, Marchand A, Reeh PW, Chaltin P, Voets T, Vriens J (2015) Activation of TRPM3 by a potent synthetic ligand reveals a role in peptide release. Proc Natl Acad Sci U S A 112:E1363-E1372.

Hinz S, Lacher SK, Seibt BF, Müller CE (2014) BAY60-6583 acts as a partial agonist at adenosine A2B receptors. J Pharmacol Exp Ther 349:427-436.

Kawabata A, Saifeddine M, Al-Ani B, Leblond L, Hollenberg MD (1999) Evaluation of proteinase-activated receptor-1 (PAR1) agonists and antagonists using a cultured cell receptor desensitization assay: activation of PAR2 by PAR1-targeted ligands. J Pharmacol Exp Ther 288:358 -370.

Kim JA, Park JY, Kang HW, Huh SU, Jeong SW, Lee JH (2006) Augmentation of Cav3.2 T-type calcium channel activity by cAMP-dependent protein kinase A. J Pharmacol Exp Ther 318:230-237.

Koch WJ, Hawes BE, Inglese J, Luttrell LM, Lefkowitz RJ (1994) Cellular expression of the carboxyl terminus of a $\mathrm{G}$ protein-coupled receptor kinase attenuates $\mathrm{G}$ beta gamma-mediated signaling. J Biol Chem 269: 6193-6197.

Meves H (2006) The action of prostaglandins on ion channels. Curr Neuropharmacol 4:41-57.

Nagakura Y, Okada M, Kohara A, Kiso T, Toya T, Iwai A, Wanibuchi F, Yamaguchi T (2003) Allodynia and hyperalgesia in adjuvant-induced arthritic rats: time course of progression and efficacy of analgesics. J Pharmacol Exp Ther 306:490-497.

Perkins MN, Campbell E, Dray A (1993) Antinociceptive activity of the bradykinin $\mathrm{B} 1$ and $\mathrm{B} 2$ receptor antagonists, des-Arg9, [Leu8]-BK and $\mathrm{HOE}$ 140, in two models of persistent hyperalgesia in the rat. Pain 53:191-197.

Petho G, Reeh PW (2012) Sensory and signaling mechanisms of bradykinin, eicosanoids, platelet-activating factor, and nitric oxide in peripheral nociceptors. Physiol Rev 92:1699-1775.

Quallo T, Alkhatib O, Gentry C, Andersson DA, Bevan S (2017) G protein $\beta \gamma$ subunits inhibit TRPM3 ion channels in sensory neurons. eLife 6: e26138.

Rohacs T (2014) Phosphoinositide regulation of TRP channels. Handb Exp Pharmacol 223:1143-1176.

Straub I, Mohr F, Stab J, Konrad M, Philipp SE, Oberwinkler J, Schaefer M (2013) Citrus fruit and fabacea secondary metabolites potently and selectively block TRPM3. Br J Pharmacol 168:1835-1850.

Touhara KK, MacKinnon R (2018) Molecular basis of signaling specificity between GIRK channels and GPCRs. Elife 7:e42908.

Veldhuis NA, Poole DP, Grace M, McIntyre P, Bunnett NW (2015) The G protein-coupled receptor-transient receptor potential channel axis: molecular insights for targeting disorders of sensation and inflammation. Pharmacol Rev 67:36-73.

Vriens J, Owsianik G, Hofmann T, Philipp SE, Stab J, Chen X, Benoit M, Xue F, Janssens A, Kerselaers S, Oberwinkler J, Vennekens R, Gudermann T, Nilius B, Voets T (2011) TRPM3 is a nociceptor channel involved in the detection of noxious heat. Neuron 70:482-494.

Wagner TF, Loch S, Lambert S, Straub I, Mannebach S, Mathar I, Düfer M, Lis A, Flockerzi V, Philipp SE, Oberwinkler J (2008) Transient receptor potential M3 channels are ionotropic steroid receptors in pancreatic $\beta$ cells. Nat Cell Biol 10:1421-1430.

Yamada M, Inanobe A, Kurachi Y (1998) G protein regulation of potassium ion channels. Pharmacol Rev 50:723-760. 